\title{
¿Seasonality of the Structure and Propagation Characteristics of the MJO
}

\author{
Ángel F. AdAmes And John M. WALlace \\ Department of Atmospheric Sciences, University of Washington, Seattle, Washington \\ JOY M. MONTEIRO \\ Centre for Atmospheric and Oceanic Sciences, and Divecha Centre for Climate Change, Indian Institute \\ of Science, Bangalore, India
}

(Manuscript received 10 August 2015, in final form 16 March 2016)

\begin{abstract}
The seasonality of the Madden-Julian oscillation (MJO) is documented in observational data, and a nonlinear shallow-water model is used to help interpret some of the contrasts in MJO structure between the boreal winter season [November-March (NDJFM)] and the Asian summer monsoon period [JuneSeptember (JJAS)]. At upper-tropospheric levels, the flanking Rossby waves remain centered around $28^{\circ} \mathrm{N} / \mathrm{S}$ year-round, but they tend to be stronger in the winter hemisphere, where the climatological-mean jet stream is stronger, rendering the subtropical circulation more sensitive to forcing by a near-equatorial heat source. Amplitudes of the MJO-related deep convection and lower-tropospheric zonal wind are stronger in the summer hemisphere, where the column-integrated water vapor is larger. During NDJFM, the equatorial asymmetry is subtle: as in the annual mean, moisture convergence into swallowtail-shaped regions of enhanced deep convection is an integral part of the equatorial Rossby wave signature, and the eastward propagation is due to moistening of the air to the east of the enhanced convection by poleward moisture advection. During the Asian summer monsoon in JJAS, the convection assumes the form of northwardpropagating, west-northwest-east-southeast-oriented rainbands embedded within cyclonic shear lines. These features are maintained by frictional convergence of moisture, and their northward propagation is mainly due to the presence of features in the climatological-mean fields: that is, the west-east moisture gradient over India and the Arabian Sea and the southwesterly low-level monsoon flow over the northwest Pacific.
\end{abstract}

\section{Introduction}

Madden and Julian $(1971,1972)$ described an intraseasonal oscillation consisting of a planetary-scale, overturning circulation in the equatorial plane coupled with a broad region of enhanced and suppressed convection centered over the warm waters of the IndoPacific warm pool $\left(60^{\circ} \mathrm{E}-180^{\circ}\right)$. In these early studies of what is now known as the Madden-Julian oscillation (MJO), no significant coherence was found between the meridional wind field and the zonal wind or precipitation anomalies. Subsequently, Zangvil (1975) noted that

\footnotetext{
¿ Denotes Open Access content.
}

Corresponding author address: Ángel F. Adames, Department of Atmospheric Sciences, University of Washington, 408 ATG Building, Box 351640, Seattle, WA 98195-1640.

E-mail: angelf88@atmos.washington.edu the convective centers in the MJO shift seasonally toward the summer hemisphere, following the belt of highest sea surface temperature (SST). Later on, Madden (1986) noted that the MJO exhibits a strong coherence between the upper-tropospheric zonal and meridional winds, but because the meridional wind component reverses direction between boreal summer and boreal winter, this relationship was not apparent in the initial analysis of Madden and Julian (1971,1972), which was based on data for all 12 calendar months. Subsequent studies by Gutzler and Madden (1989), Wang and Rui (1990), Salby and Hendon (1994), and Madden and Julian (1994) have confirmed the seasonal dependence of the amplitude, structure, and propagation characteristics of the MJO.

The MJO is more active and more symmetric with respect to the equator during the boreal winter (Wang and Rui 1990; Zhang and Dong 2004). The eastward propagation of the regions of enhanced rainfall in the equatorial belt is accompanied by southward propagation 
toward the South Pacific convergence zone (SPCZ) as they propagate eastward across the warm pool, but it is quite subtle [see Fig. 8 in Wheeler and Hendon (2004)]. In contrast, during the Asian summer monsoon (JuneSeptember), the MJO-related features are displaced toward the summer hemisphere, and the regions of enhanced convection exhibit pronounced northward propagation (Annamalai et al. 1999; Kemball-Cook and Wang 2001; Lawrence and Webster 2002; Shukla 2014).

In Adames and Wallace (2014a,b, 2015, hereafter AW1, AW2, and AW3, respectively) we investigated the three-dimensional structure of the MJO. AW1 and AW2 focused on the upper- and lower-tropospheric structure, respectively, and AW3 focused on the mechanisms that lead to the eastward propagation of the moisture anomalies. These studies were based on regression maps in which the reference time series were the two leading principal components of daily, global 850 - minus $150-\mathrm{hPa}$ velocity potential field. The results of these studies are based on data for all 12 calendar months.

In this study, we will characterize the seasonality of the MJO using the methodologies employed in AW1-AW3 in order to broaden our understanding of the physical processes that lead to the seasonal differences in the MJO's three-dimensional structure and evolution. While many previous studies have analyzed the structure and propagation of the MJO during boreal summer and winter, most of these studies have focused on a single season or are based on data for all 12 calendar months. In this study, we will elucidate on the mechanisms that lead to the seasonality in the upper-level structure of the MJO and characterize the seasonal variations in the propagation of the rain area. We will make extensive use of the "warm pool composite" developed in AW2 and extended in AW3, which yields a unified, robust description of the mean structure of the MJO averaged over a broad longitudinal sector. This compositing technique elucidates some of the robust structural elements of the MJO that have been obscured by sampling variability. Our analysis replicates features identified in previous studies of Madden (1986), Lawrence and Webster (2002), Zhang and Dong (2004), and Kikuchi et al. (2012), among others, and synthesizes them into a more coherent narrative that offers an explanation of some of the salient features of the seasonality in the MJO. In addition, we use a nonlinear shallow-water model to help interpret the seasonality of the flanking Rossby waves in the upper troposphere.

The paper is structured as follows: The next section describes the datasets and methods of analysis. The seasonal cycle in the mean state and in the MJO are shown in section 3. The seasonality in the upper-tropospheric structure in the MJO is discussed in section 4. The lowertropospheric structure of the MJO is discussed in section 5.
Section 6 discusses the seasonal variations in the MJOrelated rainbands and their poleward propagation. Results are summarized and further discussed in section 7.

\section{Data and methods}

The data and methods used in this study closely follow those in AW1-AW3. We make use of the $1.5^{\circ}$ longitude $\times$ $1.5^{\circ}$ latitude horizontal resolution and 0000 UTC daily surface and pressure level fields in the ERA-Interim dataset (Dee et al. 2011). The horizontal wind components $u$ and $v$ are used in this study as field variables and in the calculation of velocity potential $\chi$. Geopotential height $Z$, specific humidity $q$, and vertical velocity $\omega$ are also used as field variables in this study. Fields involving products of individual ERA-Interim variables are also used in section 6 . These products are calculated at each time step, and from then onward the procedure is the same as in the analysis of the individual field variables. Outgoing longwave radiation (OLR; Liebmann and Smith 1996) is also used to indicate the extent of cloud tops associated with deep convection. Unless otherwise noted, all the fields considered in this study correspond to MJO-related anomalies. We obtain these by removing the mean and first three harmonics of the annual cycle based on the 1979-2011 reference period and subtracting out the running mean of the previous 120 days in order to remove the ENSO-related signal. Regression maps for each field are obtained as in AW1-AW3:

$$
\mathbf{D}=\mathbf{S} \hat{\mathbf{P}}^{\mathrm{T}} / N
$$

where $\mathbf{D}$ is the regression pattern for a two-dimensional matrix $\mathbf{S}$, which represents the field of the variable $S$. The regression map is obtained by projecting $\mathbf{S}$ upon a standardized MJO index $\hat{\mathbf{P}}$ and dividing by the sample size $N$.

Most of the patterns shown here are obtained by regressing fields on MJO indices defined as linear combinations of the two leading principal components (PCs) of daily mean, global fields of $850-$ minus $150-\mathrm{hPa}$ velocity potential $\Delta \chi$, defined for separate seasons as indicated. A comprehensive description of this index is presented in AW1, along with a comparison of its performance with that of other MJO indices. Contour and shading intervals in the plots presented here are scaled to the approximate value of the $95 \%$ confidence interval based on a two-sided $t$ test. The leading EOFs of $\Delta \chi$ of the November-March (NDJFM) and June-September (JJAS) velocity potential fields are shown in Fig. 1 . The former strongly resembles its counterpart for the annual-mean fields shown in Fig. 1 of AW1. The latter is weaker, and its centers of action are slightly displaced toward the Northern Hemisphere, and they exhibit a northwest-southeast 

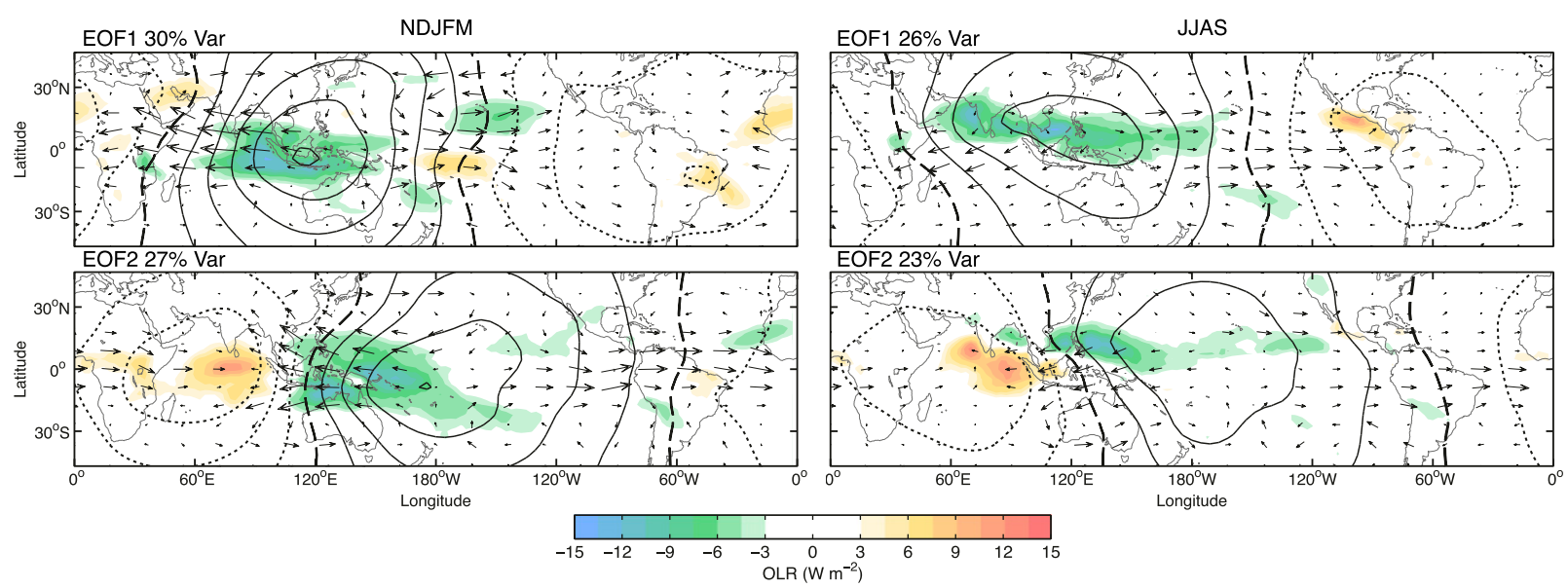

FIG. 1. Leading EOFs of 850- minus 150-hPa velocity potential $\Delta \chi$ with the corresponding regression patterns for OLR (shading) and the total 150-hPa wind vectors (arrows) based on data for (left) NDJFM and (right) JJAS: (top) EOF1 and (bottom) EOF2. Dotted (solid) contours denote negative (positive) $\Delta \chi$ anomalies, and the dashed contour depicts $\Delta \chi=0$. The contour interval is $1 \times 10^{6} \mathrm{~m}^{2} \mathrm{~s}^{-1}$. The variance explained by each mode is shown in the top-left corner of each panel. The largest wind vector is $\sim 3 \mathrm{~m} \mathrm{~s}^{-1}$.

tilt. But despite these distinctions, the planetary-scale configuration of these patterns is remarkably similar. The strongest lag correlation between PC1 and PC2 in NDJFM is 0.59 and occurs at a lag of 7 days, whereas in JJAS it is 0.47 and also occurs at a lag of 7 days.

Many of the fields in this study are "warm pool composites," generated using the analysis technique described in AW2 and AW3. For the two contrasting seasons, NDJFM and JJAS, we generate a series of regression maps based on linear combinations of PC1 and PC2 of $\Delta \chi$ for the MJO phases in which the $\Delta \chi$ maximum is centered over the Indo-Pacific warm pool $\left(60^{\circ} \mathrm{E}-\right.$ $180^{\circ}$ ). A warm pool composite (WPC) corresponding to the time when the MJO is active over the Maritime Continent (maximum PC1, denoted WPC1) is generated by zonally shifting each member of the sequence of maps such that the longitude at which $\Delta \chi$ is a maximum corresponds to the reference longitude $\left(0^{\circ}\right)$. An analogous composite, but for the time when the MJO is active over the Indian Ocean (minimum PC2, denoted WPC2), is made in the same way, but using the node in $\Delta \chi$ in which $\partial \Delta \chi / \partial x$ is negative instead of the maximum in $\Delta \chi$. In this study, we create an MJO cycle using warm pool composites by using linear combinations of WPC1 and WPC2.

\section{Seasonality}

Before exploring the seasonality of the MJO itself, we document the seasonality of the background climatology. Figure 2 shows latitude-calendar month sections of zonally averaged 200-hPa zonal wind (contours) and vertically integrated specific humidity. The zonal averaging is limited to the warm pool sector $60^{\circ} \mathrm{E}-180^{\circ}$, where the $\mathrm{MJO}$ is most active, as in Zhang and Dong (2004). In this sector, the belt of high vertically integrated moisture migrates from $\sim 5^{\circ} \mathrm{S}$ in the boreal winter to $\sim 7^{\circ} \mathrm{N}$ in the boreal summer, collocated with the seasonal march in SSTs and following the insolation by about a month. The boreal spring transition occurs in April; the autumn transition is more gradual and occurs a month or two later relative to the equinox. The jets near $30^{\circ} \mathrm{N} / \mathrm{S}$ are most prominent during the respective winter seasons.

Figure 3 illustrates the seasonality in the root-meansquare (RMS) amplitude of the MJO in the same format.

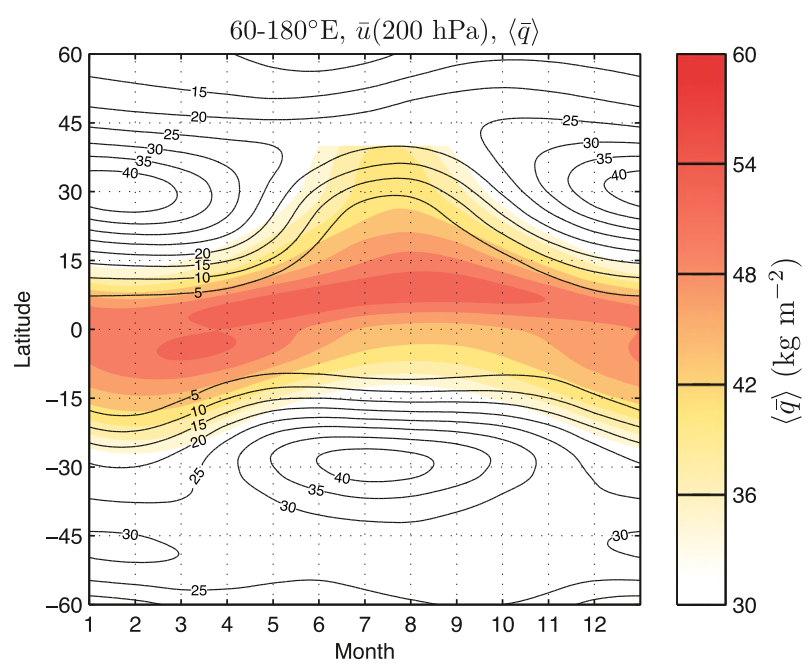

FIG. 2. Monthly distribution of warm pool-averaged $\left(60^{\circ} \mathrm{E}-180^{\circ}\right)$ column-integrated water vapor $\langle q\rangle$ (shaded) and $200-\mathrm{hPa}$ mean zonal wind $u$ (contoured). The contour interval is $5 \mathrm{~m} \mathrm{~s}^{-1}$. Only positive (westerlies) mean winds are shown. 

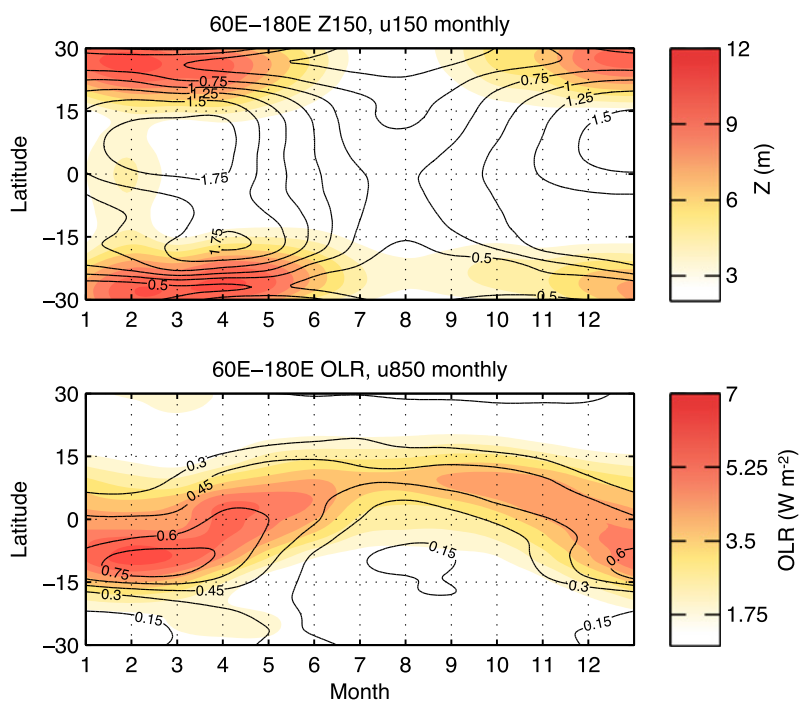

FIG. 3. Monthly distribution of warm pool-averaged $\left(60^{\circ} \mathrm{E}-180^{\circ}\right)$ RMS amplitude of (top) MJO-related 150-hPa zonal wind anomalies $u$ (contoured) and $150-\mathrm{hPa}$ geopotential height anomalies $Z$ (shaded). The contour interval is $0.5 \mathrm{~m} \mathrm{~s}^{-1}$. (bottom) RMS amplitude of MJO-related OLR (shaded) and $850-\mathrm{hPa}$ zonal wind anomalies. The contour interval is $0.25 \mathrm{~m} \mathrm{~s}^{-1}$. The fields are linear regressions based on $\mathrm{PC} 1$ and $\mathrm{PC} 2$ of $\Delta \chi$ for time series based on individual months of the calendar year.

As in AW1, RMS amplitude is defined as $D_{\text {rms }}=$ $(1 / 2) \sqrt{D_{1}^{2}+D_{2}^{2}}$, where $D_{1}$ and $D_{2}$ are regression maps of PC1 and PC2 of $\Delta \chi$, respectively. The top panel shows geopotential height $Z$ and zonal wind $u$ at the $150-\mathrm{hPa}$ level. The flanking Rossby waves, with pronounced maxima in the RMS $Z$ field along $28^{\circ} \mathrm{N} / \mathrm{S}$ are strong in both hemispheres from December through April and weaken abruptly in May. They virtually disappear in the Northern Hemisphere during the boreal summer monsoon, when the Tibetan anticyclone interrupts the westerly waveguide. However, traces of the flanking Rossby waves in the $Z$ field are still detectable in the Southern Hemisphere throughout this season. During the boreal autumn, October and November, the flanking Rossby waves recover gradually in both hemispheres. Equatorward of $28^{\circ} \mathrm{N} / \mathrm{S}$, the zonal wind RMS amplitude exhibits an analogous seasonality.

The bottom panel of Fig. 3 shows the corresponding RMS amplitude plot for OLR (shading) and 850-hPa zonal wind (contours). In contrast to the MJO seasonality in the upper troposphere, which is dominated by variations in the amplitude of the flanking Rossby waves along $28^{\circ} \mathrm{N} / \mathrm{S}$, the seasonality in the lower troposphere is dominated by a meridional shifting of the equatorial band of maximum amplitude, northward during April and May, and back southward from 1 September until the end of the calendar year. Amplitudes are stronger during the boreal winter, but the MJO signature is clearly detectable year-round. The north-south excursions of the belt of highest RMS amplitude in OLR and zonal wind track the belt of highest climatological-mean specific humidity, as inferred by comparing these fields with the mean column-integrated water vapor in Fig. 2 and as pointed out by Zhang and Dong (2004).

In the remainder of this section and the next two sections we will contrast the structure and evolution of the MJO during the boreal winter and summer seasons NDJFM and JJAS, respectively. The former has been widely used as a basis for studies of the Northern Hemisphere general circulation and the latter for studies of the Asian summer monsoon. It is evident from Fig. 3 that the MJO structure during these seasons, though not perfectly homogeneous within them, is representative of the strongest seasonal contrasts. We have experimented with alternative definitions of the seasons and found that a shift of a month in the beginning or end dates has very little effect.

\section{Flanking Rossby waves}

Zonal-mean RMS amplitudes of anomalous geopotential height $Z$, zonal mass flux $\rho u$, and vertical velocity $\omega$ are shown in Fig. 4. In contrast to Figs. 2 and 3, these represent full zonal averages, analogous to the plots in Fig. 13 of AW1 and Fig. 1 of AW2. Consistent with Fig. 3a, during NDJFM, flanking Rossby waves are evident in both hemispheres along $28^{\circ} \mathrm{N} / \mathrm{S}$ equatorward of the cores of the climatological-mean westerly jets, and they are stronger in the Northern Hemisphere. During JJAS, when the Tibetan anticyclone interrupts the westerly waveguide, their signature in the Northern Hemisphere is weak, but a substantial signal is still evident in the Southern Hemisphere. Teleconnections to higher latitudes of both hemispheres are evident during NDJFM and in the Southern Hemisphere during its winter season, JJAS. The signature of the flanking Rossby waves in the upper-tropospheric zonal mass flux and vertical velocity fields (Figs. $4 b, c$ ) are largely restricted to the winter hemisphere. In contrast, the lowertropospheric zonal mass flux and equatorial vertical velocity are shifted toward the summer hemisphere. It was shown by Barlow et al. (2005), Hoell et al. (2012), and AW2 that the regions of ascent associated with the flanking Rossby waves are induced by the advection of temperature anomalies in the flanking Rossby waves by the zonal-mean wind, both of which tend to be stronger in the winter hemisphere.

The structure of the flanking Rossby waves is revealed in further detail in the warm pool composite centered at the time when PC1 is maximum (WPC1) of $100-300-\mathrm{hPa}$ 

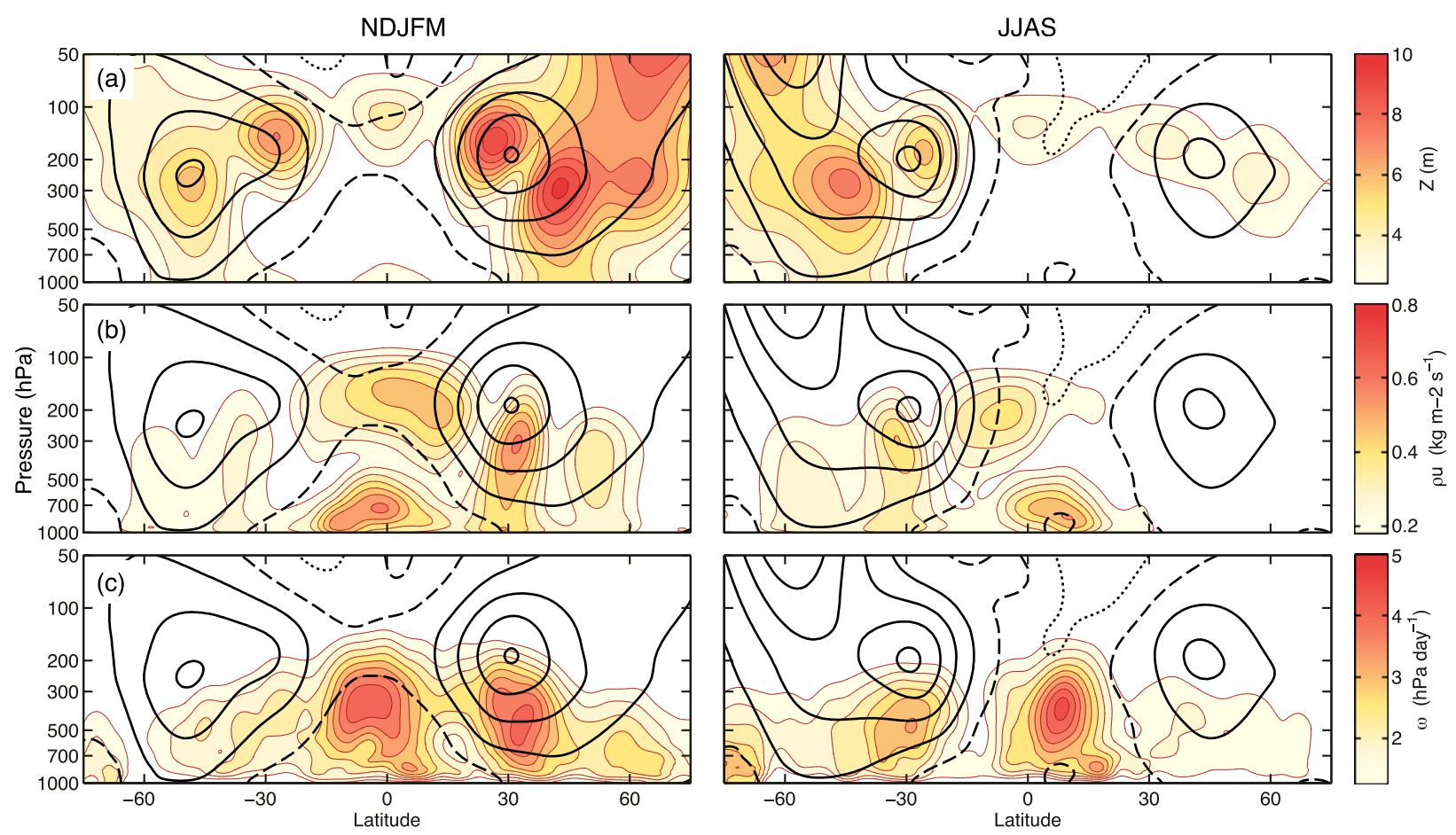

FIG. 4. RMS amplitude of MJO-related anomalies during (left) NDJFM and (right) JJAS obtained from the regression patterns based on PC1 and PC2 of $\Delta \chi$, overlaid by the climatological-mean zonal wind field for each season (contours; interval is $10 \mathrm{~m} \mathrm{~s}^{-1}$ ). The shaded fields are (a) geopotential height $Z$, (b) zonal mass flux $\rho u$, and (c) vertical velocity $\omega$.

geopotential height and zonal wind for NDJFM and JJAS shown in Fig. 5. (See section 2 for specifics of the compositing scheme.) The quadrupole pattern in NDJFM resembles the annual-mean flanking Rossby wave configuration shown in the top panel of Fig. 7 of AW2. However, in agreement with Figs. 2 and 4, the centers of action in the height field tend to be stronger in the winter hemisphere and stronger in the Northern Hemisphere
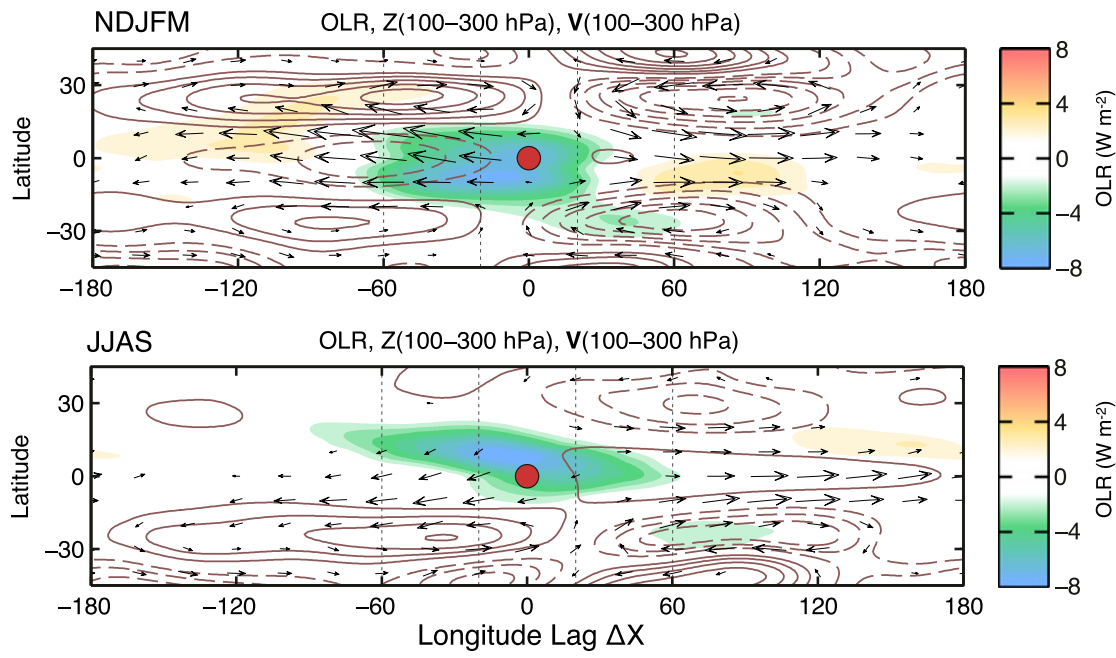

FIG. 5. Warm pool composite WPC1 of (top) NDJFM and (bottom) JJAS OLR (shaded) and $100-300-\mathrm{hPa}$-averaged $Z$ (contours; interval is $1.5 \mathrm{~m}$ ) and horizontal winds (arrows). Only arrows corresponding to wind anomalies that are found to be statistically significant at the $95 \%$ confidence interval are shown. The largest wind vector is $\sim 2 \mathrm{~m} \mathrm{~s}^{-1}$. 
during NDJFM than in the Southern Hemisphere in JJAS. In addition, there are subtle east-west asymmetries in the strengths and placements of the individual centers. For example, in the summer hemisphere, the centers to the east of the heat source are stronger than the centers to the west of it.

Monteiro et al. (2014) used a nonlinear shallow-water model to investigate the role of the climatological-mean flow in determining the structure of the flanking Rossby waves in the MJO for annual-mean conditions. In their study, the climatological-mean jets and the heat source were both prescribed to be symmetric with respect to the equator. Here, we explore whether shifting the heat source away from the equator and breaking the equatorial symmetry of the climatological-mean jet streams can explain the observed seasonality in the structure of the flanking Rossby waves. For this purpose, we use the Geophysical Fluid Dynamics Laboratory's flexible modeling system's spherical nonlinear shallow-water model. Details of the experimental setup are summarized below, and the reader is referred to Monteiro et al. (2014), Kraucunas and Hartmann (2007), and Bao and Hartmann (2014) for further information on the model and the experimental setup.

Experiments are conducted by prescribing a spatially uniform resting fluid depth $h$, which determines the Rossby radius of deformation $\sqrt{g h} / f$ and the amplitude of the barotropic wave response. The simulated climatologicalmean flow is generated by prescribing a zonally symmetric, meridionally varying topography of the form

$$
H_{b}(\theta)=H_{0}\left[1-\left(\sin \theta-\sin \theta_{0}\right)^{N}\right],
$$

where $H_{0}, \theta_{0}$, and $N$ are the maximum topographic height, the reference latitude, and a constant, respectively. The model is spun up for 25 days using the above forcing to generate a steady-state background flow consisting of two jets whose amplitude and location are determined by the forcing (for the full set of equations, see supplementary material in Monteiro et al. 2014). We use values of $H_{0}=2000 \mathrm{~m}$ and $N=2$, which yields a mean state with climatological-mean jet streams located at around $30^{\circ} \mathrm{N} / \mathrm{S}$. At day 25 , a heat source of the following form is turned on:

$$
\begin{aligned}
Q^{\prime}(\lambda, \theta)= & \left.Q_{0} \exp \left[-\left(\theta-\theta_{p}\right)^{2} / L_{y}^{2}-\left(\lambda-\lambda_{p}\right)^{2} / L_{x}^{2}\right)\right] \\
& -\bar{Q}(\theta),
\end{aligned}
$$

where $\theta$ is the latitude, $\theta_{p}$ is the latitude of the center of the heat source, $\lambda$ is the longitude, $\lambda_{p}$ is the longitude of the center of the heat source, and $L_{x}$ and $L_{y}$ respectively determine the zonal and meridional extent of the heating. For all simulations, the zonal mean of the heat source $\bar{Q}$ is removed in order to prevent a zonal-mean response from developing in the model. Even though the MJO is a propagating disturbance, the heat source prescribed here is stationary. It can be shown that the vorticity tendency arising from MJO propagation is negligibly small when compared to the other terms in the vorticity balance discussed in this section. Equilibrium is achieved by day 45 [see Fig. 4 in Monteiro et al. (2014)]. We will analyze model output from day 99.

Figure 6a shows the wave response to a heat source $Q^{\prime}$ centered on the equator $\left(\theta_{p}=0\right)$ for a stationary basic state $\left(H_{0}=0 \mathrm{~m}\right)$ and a resting fluid depth of $h=600 \mathrm{~m}$. The response is composed of equatorially symmetric Rossby waves and a Kelvin wave response, as in Matsuno (1966) and Gill (1980). The Kelvin wave response to the east of the heat source is muted, and a quadrupole Rossby wave response is observed rather than a couplet to the west of the heat source. These departures from the canonical Matsuno-Gill solution are due to removal of the zonal mean of the heat source $\bar{Q}$, which yields an elongated heat sink to the east and west of the heat source [see Fig. 1 in Bao and Hartmann (2014)]. When the heat source is shifted $5^{\circ}$ to the south of the equator, as shown in Fig. 6b, most of the upper-level divergence from the heat source shifts into the Southern Hemisphere, where the advection of planetary vorticity by the anomalous meridional winds strengthens in order to satisfy Sverdrup balance $\left(f \nabla \cdot \mathbf{V}^{\prime}=-v^{\prime} \partial_{y} f\right)$, leading to a stronger Rossby wave response, as in Fig. 3 of Gill (1980) and Fig. 5 of Phlips and Gill (1987). This response, however, does not match the observed uppertropospheric structure of the MJO in Fig. 5a, because the Rossby wave response is too equatorially focused, and the strongest response in observations is in the winter, rather than the summer, hemisphere.

Figure $7 \mathrm{~b}$ shows the response to a heat source centered on $5^{\circ} \mathrm{S}$ (as in Fig. $5 b$ ) with equatorially symmetric jets centered near $30^{\circ} \mathrm{N} / \mathrm{S}$, as indicated in Fig. 7a. Incorporation of the climatological-mean jets substantially widens the meridional extent of the wave response. In these simulations, the vorticity balance of the Rossby wave response is modulated by the advection of eddy relative vorticity by the climatological-mean flow $\bar{u}$. Thus, as discussed in Monteiro et al. (2014), the vorticity $(\zeta)$ balance equation in the flanking Rossby waves is of the form

$$
\bar{\zeta} \nabla \cdot \mathbf{V}^{\prime}+\bar{u} \frac{\partial \zeta^{\prime}}{\partial x}=-v \frac{\partial \bar{\zeta}}{\partial y},
$$

where $\bar{\zeta}=f-\bar{u}_{y}$ is the mean absolute vorticity. For a symmetric pair of jets, the flanking Rossby wave response is stronger in the hemisphere with the stronger diabatic heating. 


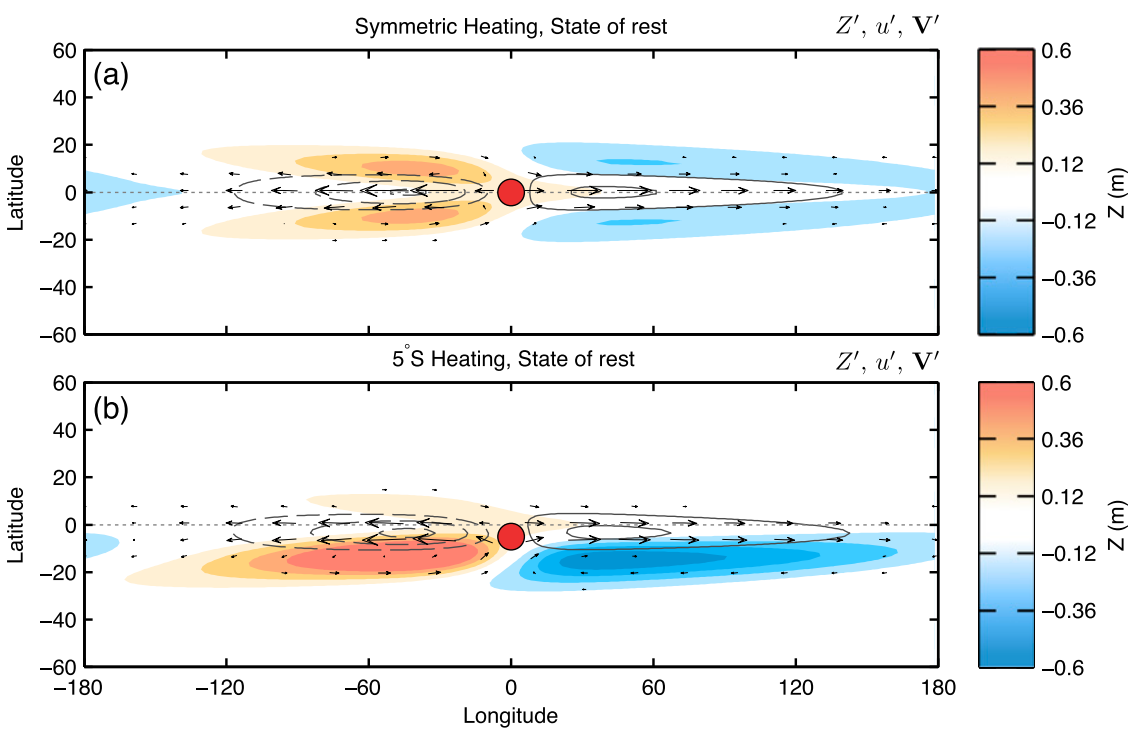

FIG. 6. Stationary eddy geopotential height field $Z$ (shading) and winds (arrows; $u$ is contoured; interval is $0.2 \mathrm{~m} \mathrm{~s}^{-1}$ ) for the zero-basic-state-flow simulations for a heat source (a) located over the equator and (b) shifted $5^{\circ}$ south of the equator. The location of the center of the heat source is marked by a red circle in both panels. The equator is marked by a gray dotted line. The longest arrow in all panels corresponds to a wind speed of $\sim 0.7 \mathrm{~m} \mathrm{~s}^{-1}$.

In Figs. $7 \mathrm{c}$ and $7 \mathrm{~d}$ the amplitude of the climatological jets is designed to mimic the observed configuration during the boreal winter, when the Northern Hemisphere jet is nearly twice as strong as its Southern
Hemisphere counterpart. Because of this asymmetry, the flanking Rossby wave response is stronger in the winter hemisphere, despite the fact that the heat source is shifted toward the summer hemisphere. The zonal
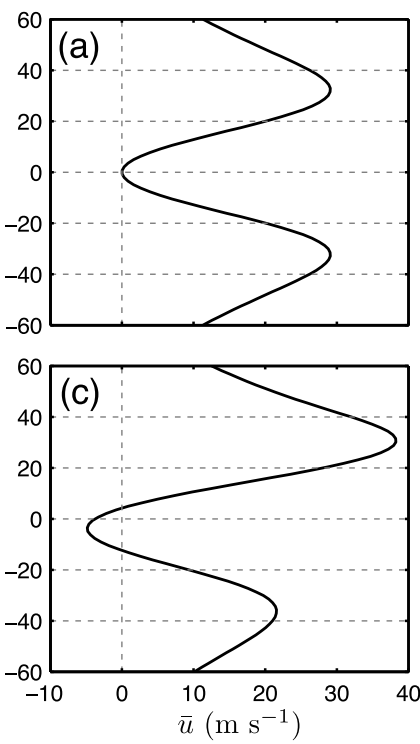
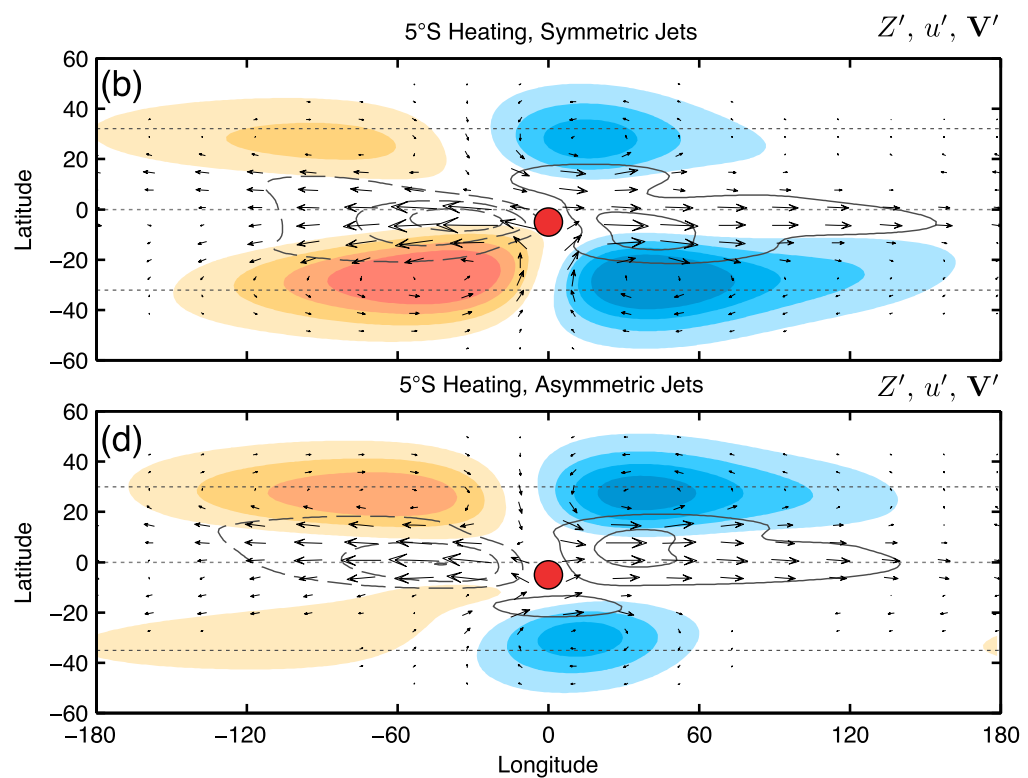
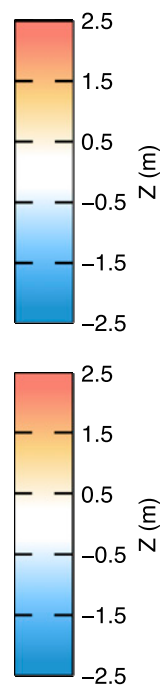

FIG. 7. Stationary eddy geopotential height field $Z$ (shading) and winds (arrows; $u$ is contoured; interval is $0.2 \mathrm{~m} \mathrm{~s}^{-1}$ ) for flow simulations with a heat source shifted $5^{\circ}$ south of the equator and (a),(b) equatorially symmetric climatological-mean jets and (c),(d) westerly jets similar to those observed during the boreal winter. The location of the center of the heat source is marked by a red circle in (b) and (d). The gray dashed lines in (b) and (d) correspond to the equator and the latitude where the westerly jets reach maximum amplitude. The longest arrow in all panels corresponds to a wind speed of $\sim 0.7 \mathrm{~m} \mathrm{~s}^{-1}$. 
wind anomalies are also shifted toward the Northern Hemisphere, consistent with the observed uppertropospheric structure of the MJO during boreal winter. These results are consistent with prior findings of Kraucunas and Hartmann (2007) relating equatorial asymmetries in the equatorial planetary waves to equatorial asymmetries in basic-state flow and in the latitude of the heat source. As in the warm pool composites shown in Fig. 5, the centers of action of the simulated flanking Rossby waves in the winter hemisphere are displaced to the east of their counterparts in the summer hemisphere.

\section{OLR and lower-tropospheric wind}

In contrast to the MJO's flanking Rossby waves, whose amplitude is seasonally varying but whose latitude remains nearly fixed near $28^{\circ} \mathrm{N} / \mathrm{S}$, the deep convection and the associated features in the lower-tropospheric zonal wind field migrate back and forth across the equator so as to be centered in the tropics of the summer hemisphere, where SST and column-integrated water vapor are highest, as shown in Fig. 1.

Now let us consider the contrasting structure of the MJO-related OLR and lower-tropospheric geopotential height $Z$ and wind anomalies during boreal winter and summer. Five-panel sequences, constructed using the warm pool compositing technique described in section 2 , are shown in Fig. 8. The panels in the two columns are snapshots at $1 / 8$-cycle intervals spanning half a cycle. Figure $8 \mathrm{c}$ describes the conditions associated with the peak of PC1 of $\Delta \chi$, and Fig. 8e represents conditions at the time of maximum PC2. During NDJFM (left column), a patch of convection initially develops over the western part of the domain and propagates eastward with a slight southward displacement, weakening as it approaches the eastern side of the warm pool domain. As the OLR anomalies propagate eastward, the associated zonal wind anomalies become progressively stronger, as also noted in studies by Zhang and McPhaden (2000), Wheeler and Hendon (2004), and Kiladis et al. (2005). The structure is, to first order, equatorially symmetric, and it strongly resembles the regression maps based on yearround data discussed in AW1, AW2, and AW3.

The corresponding patterns for JJAS, shown in the right column of Fig. 8 are dominated by a west-northwest-eastsoutheast-tilted rainband in the tropics of the Northern Hemisphere that propagates eastward and northward in the five-panel sequence, consistent with the patterns described by Wang and Xie (1997), Lawrence and Webster (2002), Krishnamurthy and Shukla (2008), Lee et al. (2013), and others. In the early panels in the sequence, the rainband is preceded by a band of easterly wind anomalies, while in the later panels it is followed by a band of westerly wind anomalies, which is similar to the observed sequence in NDJFM.

Another way of contrasting the meridional structure of the MJO during the boreal winter and summer seasons is by constructing time-latitude sections by regressing the OLR and lower-tropospheric zonal wind fields upon the same linear combinations of PC1 and PC2 of $\Delta \chi$ as were used in constructing Fig. 8. Sections for $70^{\circ}-100^{\circ}, 100^{\circ}-130^{\circ}$, and $130^{\circ}-160^{\circ} \mathrm{E}$ are shown in Fig. 9. In NDJFM (Figs. 9a-c), there is poleward propagation of the OLR and zonal wind anomalies in both hemispheres. Southward propagation in the Southern Hemisphere is dominant over the western part of the domain, where the zonal wind perturbations reach $10^{\circ} \mathrm{S}$ about a week after they first appear over the equator. Over the western Pacific, the northward propagation in the Northern Hemisphere is almost as pronounced as the southward propagation in the Southern Hemisphere. These patterns are consistent with the eastward passage of regions of enhanced convection that exhibit the characterized "swallowtail shape" described by Zhang and Ling (2012) and in the warm pool composites shown in AW2.

The corresponding sections for JJAS (Figs. 9d-f) are characterized by (meridionally) narrower and more slowly northward-propagating rainbands originating in the equatorial belt, accompanied by zonal wind perturbations. The northward propagation is most pronounced in the westernmost section, which corresponds to the Indian Ocean sector, but it is also present in the middle section, which extends from Indochina to the east of the Philippines, and in the eastern section centered just to the east of the Philippines. That the zonal wind perturbations and OLR perturbations are in quadrature with negative OLR anomalies poleward of westerly wind anomalies indicates that the northwardpropagating rainbands coincide with cyclonic shear zones, as pointed out in previous studies of the so-called monsoon intraseasonal oscillation (MISO) (Hoyos and Webster 2007; Krishnamurthy and Shukla 2008; Shukla 2014).

The features in the section for $70^{\circ}-100^{\circ} \mathrm{E}$ for JJAS are clearly displaced toward the Northern Hemisphere, like those shown by Jiang et al. (2011), whereas those shown in Fig. 6 of Waliser et al. (2009) are more equatorially symmetric. We have confirmed that this distinction is real. It is likely due to the fact that our sections are constructed by regressing the OLR and zonal wind fields on MJO indices, whereas theirs were constructed by regressing those fields on the equatorial OLR anomalies themselves. Hence, their sections may include variability that is not correlated with our MJO indices. 
NDJFM
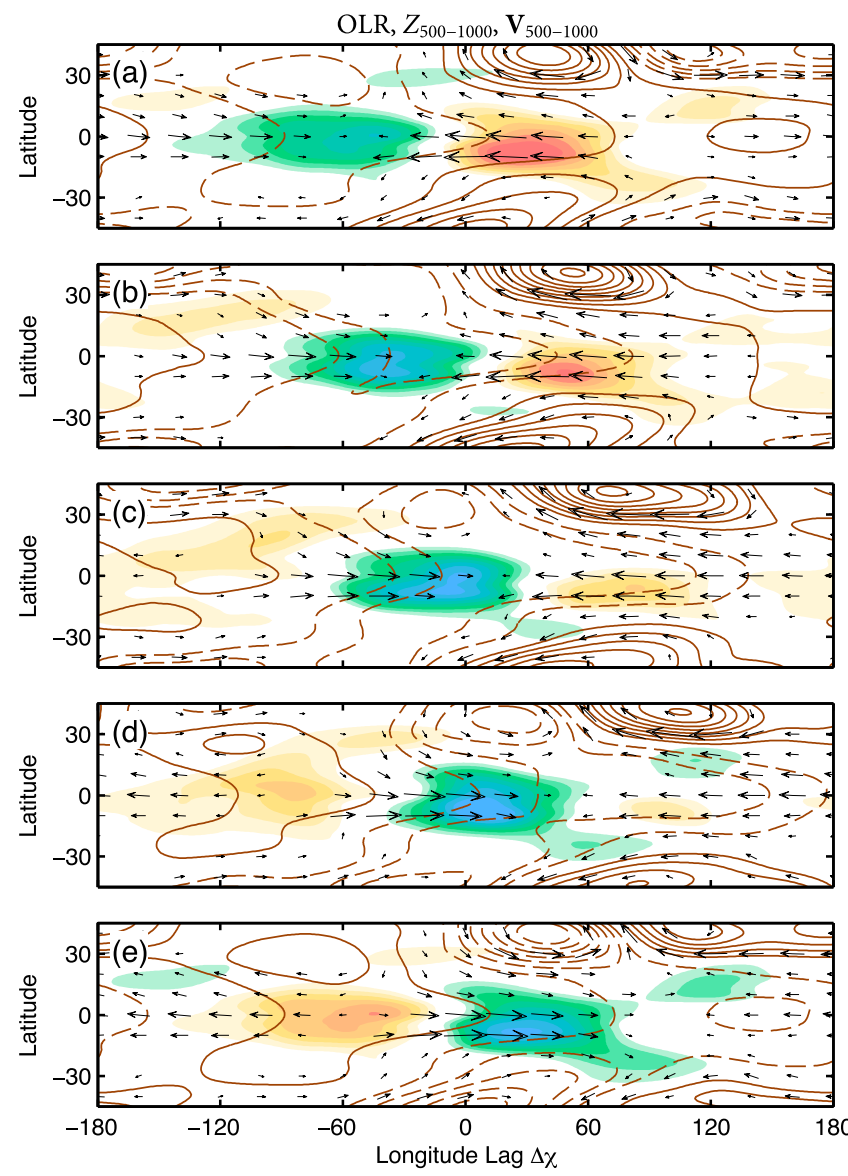

JJAS
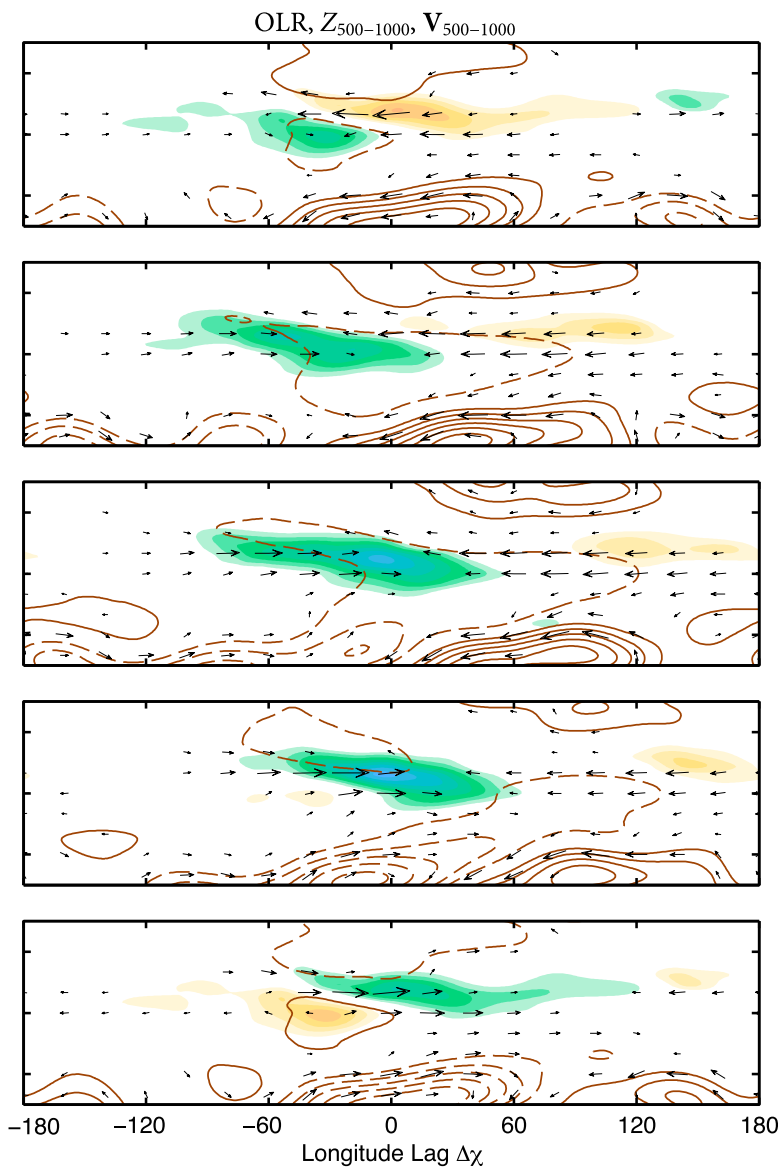

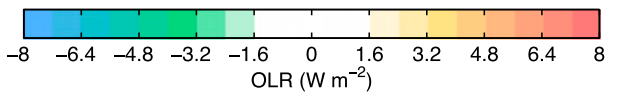

FIG. 8. Warm pool composite of (left) NDJFM and (right) JJAS OLR (shaded), 500-1000-hPa-averaged $Z$ anomalies (contours; interval is $1.5 \mathrm{~m}$ ), and $500-1000-\mathrm{hPa}$-averaged winds (arrows) for linear combinations of warm pool composites based on the $\Delta \chi$ maximum (WPC1), representative of convection at the time of maximum PC1, and the node in $\Delta \chi$ (WPC2), representative of the time of maximum PC2. (a) WPC2, (b) $(\mathrm{WPC} 1+\mathrm{WPC} 2) / \sqrt{2}$, (c) WPC1, (d) (WPC1 - WPC2) $/ \sqrt{2}$, and (e) $-\mathrm{WPC} 2$. The reference longitude $\left(0^{\circ}\right)$ corresponds to the location of the $\Delta \chi$ maximum at the time of WPC1. The largest wind vector is $\sim 1 \mathrm{~m} \mathrm{~s}^{-1}$.

\section{Seasonality of the maintenance and propagation of the rain areas}

Studies of tropical dynamics dating back to Charney and Eliassen (1964) have shown how frictionally induced boundary layer convergence in regions of cyclonic low-level flow provides the lifting that maintains and in some cases amplifies tropical weather systems. In AW2, we showed that this mechanism is operative in maintaining the robust swallowtail shape of the equatorial regions of enhanced convection in the MJO. Here, we examine the seasonality of the frictional convergence and the convergence in the lower free troposphere, and we show how they contribute to the contrasting and propagation of the rainbands.
Figure 10a shows vector wind and divergence fields averaged over the lower free troposphere $(850-500 \mathrm{hPa})$, and Fig. 10b shows the same fields averaged over the boundary layer $(1000-850 \mathrm{hPa})$. These are warm pool composites based on $\mathrm{PC} 1$ of $\Delta \chi$ (WPC1), as in AW2, which describe the MJO at the time when the enhanced convection is centered over the Maritime Continent. Lower-freetropospheric convergence during NDJFM is slightly shifted toward the Southern Hemisphere. The boundary layer divergence field is similar to that seen in composites based on all 12 calendar months, except that the convergence is stronger in the Southern Hemisphere. The observed asymmetry is consistent with the amplified equatorial Rossby wave response to a heat source shifted slightly to the south of the equator, as in the simulations shown in 

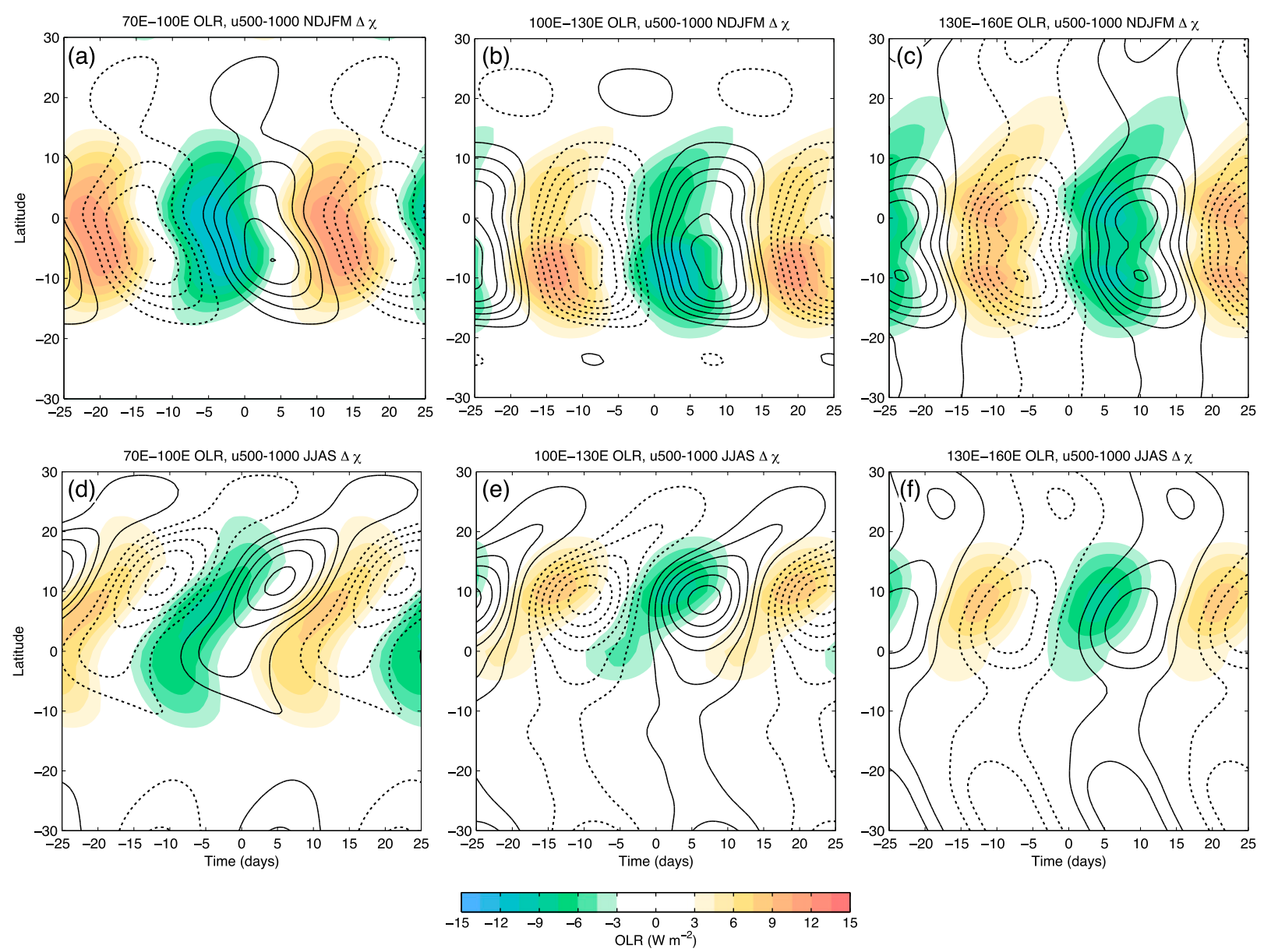

FIG. 9. Time-latitude sections of partially zonally averaged OLR (shaded) and 500-1000-hPa-averaged $u$ (contours; interval is $0.2 \mathrm{~m} \mathrm{~s}^{-1}$ ) for (a)-(c) NDJFM and (d)-(f) JJAS averaged over (left) $70^{\circ}-100^{\circ}$, (center) $100^{\circ}-130^{\circ}$, and (right) $130^{\circ}-160^{\circ} \mathrm{E}$. The sections are based on linear combinations of PC1 and PC2 of $\Delta \chi$ and a 40-day cycle.

Fig. 6b. Note that the anomalies in Fig. 10 are of opposite polarity to the anomalies in Fig. 6, since these figures correspond to the lower and upper troposphere, respectively. Boundary layer and free-tropospheric convergence are roughly comparable in magnitude and thus contribute about equally to the observed structure of the rain area, depicted by the OLR anomalies in Fig. 5a.

During JJAS, the divergence field in the free lower troposphere is dominated by the zonal wind component. It is displaced only slightly toward the Northern Hemisphere, and it evidently does not contribute substantially to maintaining the rainbands observed in the OLR field. It is only about half as strong as the anomalous lowerfree-tropospheric convergence observed in NDJFM. In contrast, the boundary layer divergence field is dominated by a west-northwest-east-southeast-tilting convergence line, which corresponds with a band of cyclonic shear, with equatorial westerlies to the south of it. That boundary layer (BL) convergence dominates in JJAS implies that the profile of vertical velocity is more bottom heavy (ascent peaks lower in the troposphere) during JJAS than during NDJFM.

Analysis of the MJO's moisture budget is helpful in understanding the seasonal contrasts in the propagation of the MJO, in particular the northward propagation of the rainbands during JJAS. The column-integrated intraseasonal moisture tendency equation for the MJOrelated anomalies takes the following form:

$$
\frac{\partial\left\langle q^{*}\right\rangle}{\partial t}=-\left\langle(\mathbf{V} \cdot \nabla q)^{*}\right\rangle-\left\langle\left(\omega \frac{\partial q}{\partial p}\right)^{*}\right\rangle-\frac{\left\langle Q_{2}^{*}\right\rangle}{L_{v}},
$$

where asterisks correspond to 20-100-day-filtered anomalies, extracted by using a 101-point Lanczos filter (Duchon 1979), and the angle brackets represent a mass-weighted integral from 100 to $1000 \mathrm{hPa}$. The first term on the 
NDJFM

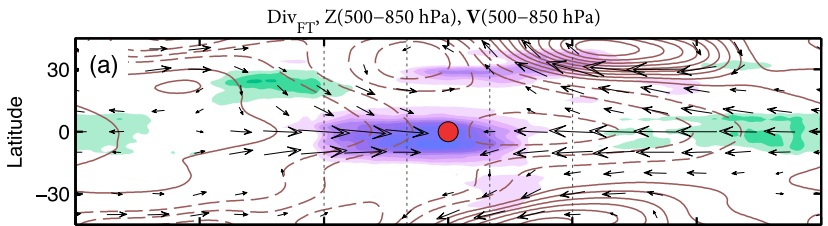

$\mathrm{Div}_{\mathrm{BL}}, \mathrm{Z}(850-1000 \mathrm{hPa}), \mathrm{V}(850-1000 \mathrm{hPa})$

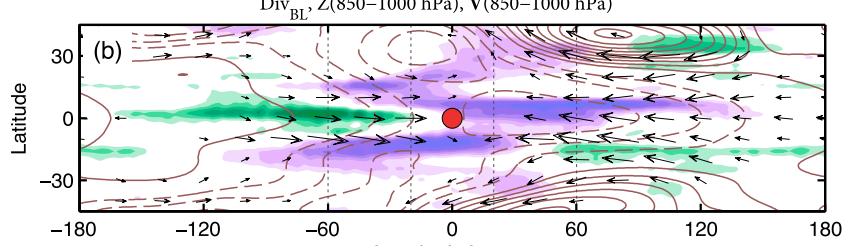

Longitude Lag $\Delta \chi$

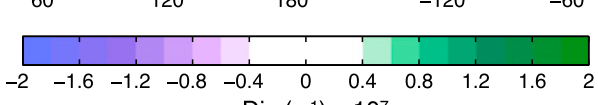

JJAS

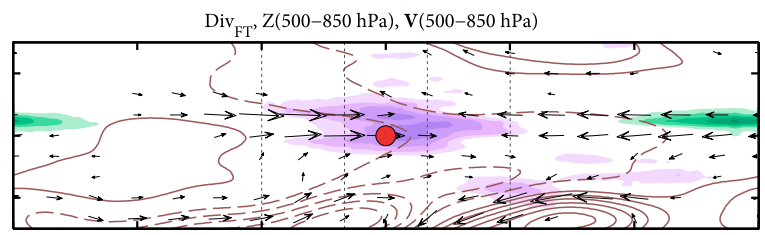

$\operatorname{Div}_{B \mathrm{~B}}, \mathrm{Z}(850-1000 \mathrm{hPa}), \mathrm{V}(850-1000 \mathrm{hPa})$

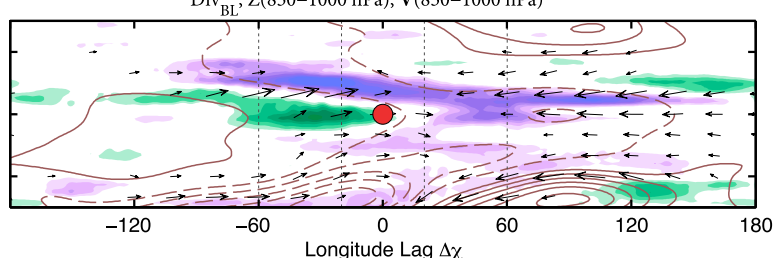

Longitude Lag $\Delta x$

$\operatorname{Div}\left(\mathrm{s}^{-1}\right) \times 10^{7}$

FIG. 10. WPC1 of (left) NDJFM and (right) JJAS: (a) lower-free-tropospheric (500-850-hPa averaged) divergence (shaded), Z, and horizontal wind anomalies (arrows). (b) As in (a), but averaged over the boundary layer (850-1000 $\mathrm{hPa}$ ). Only arrows corresponding to wind anomalies that are found to be statistically significant at the $95 \%$ confidence interval are shown. The largest wind vector is $\sim 0.75 \mathrm{~m} \mathrm{~s}^{-1}$

right-hand side represents the contribution of horizontal advection, the second represents vertical moisture advection, and the third is the apparent moisture sink $Q_{2}$ (Yanai et al. 1973). The sum of the second and third terms is referred to by Chikira (2014) and Wolding and Maloney (2015) as the moistening from "column processes." Figure 11a shows a warm pool composite of column-integrated water vapor $\left\langle q^{*}\right\rangle$ and its tendency $\partial\left\langle q^{*}\right\rangle / \partial t$. The composites shown here correspond to the time in the MJO cycle when convection is a maximum over the Indian Ocean (minimum PC2), denoted as WPC2, though similar (albeit less clear) results are
NDJFM
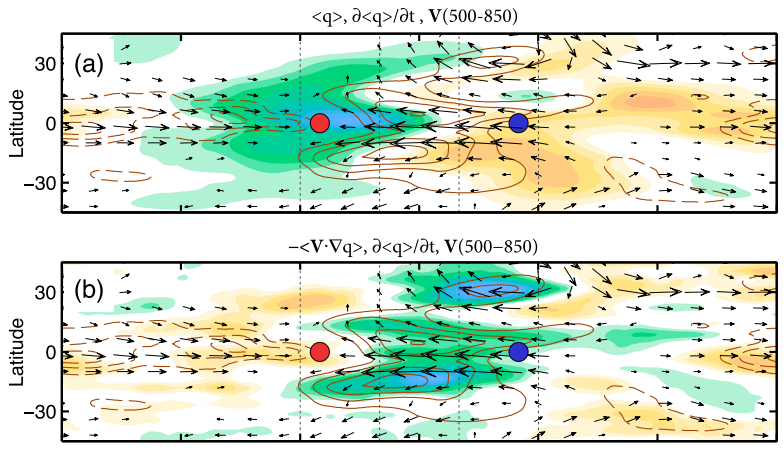

$-<\omega \partial \mathrm{q} / \partial \mathrm{p}>-<\mathrm{Q}_{2}>/ \mathrm{L}_{\mathrm{v}}, \partial<\mathrm{q}>/ \partial \mathrm{t}, \mathrm{V}(500-850)$

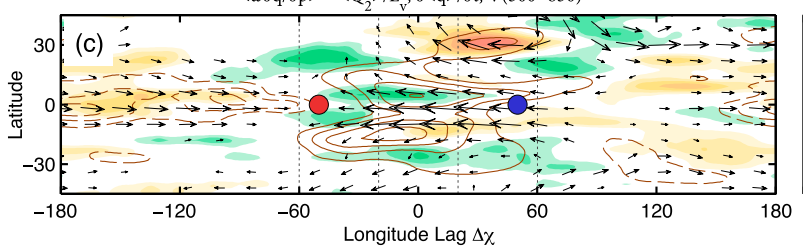

JJAS

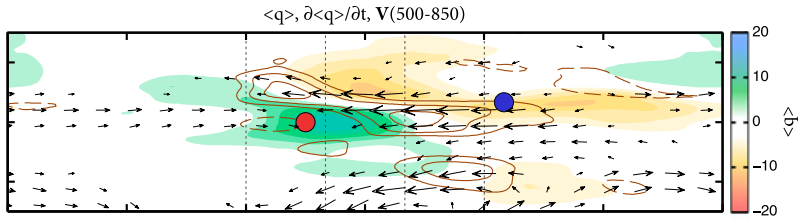

$-<\mathrm{V} \cdot \nabla \mathrm{q}>, \partial<\mathrm{q}>/ \partial \mathrm{t}, \mathrm{V}(500-850)$

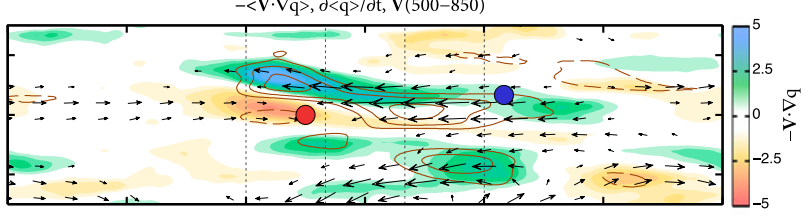

$-<\omega \partial \mathrm{q} / \partial \mathrm{p}>-<\mathrm{Q}_{2}>/ \mathrm{L}_{\mathrm{v}}, \partial<\mathrm{q}>/ \partial \mathrm{t}, \mathrm{V}(500-850)$

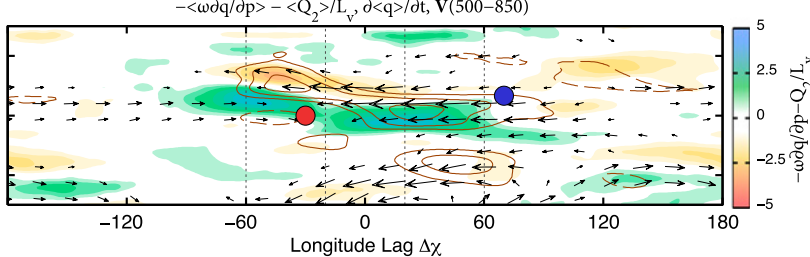

FIG. 11. WPC2 of (left) NDJFM and (right) JJAS: (a) anomalous column-integrated water vapor $\left\langle q^{*}\right\rangle$ (shaded), (b) anomalous columnintegrated horizontal moisture advection $(-\mathbf{V} \cdot \nabla q) *($ shaded), and (c) the column-integrated net moistening from vertical moisture advection and the apparent moisture source/sink $Q_{2}^{*}$ (shaded). The tendency of $\left\langle q^{*}\right\rangle$, that is, $\partial\left\langle q^{*}\right\rangle / \partial t$, and the 500-850-hPa-averaged wind field are shown as contours (interval is $0.025 \mathrm{~kg} \mathrm{~m}^{-2} \mathrm{day}^{-1}$ ) and arrows, respectively, in all panels. Shading is in units of $10^{-1} \mathrm{~kg} \mathrm{~m}^{-2}$. Only arrows corresponding to wind anomalies that are found to be statistically significant at the $95 \%$ confidence interval are shown. The largest wind vector is $\sim 1 \mathrm{~m} \mathrm{~s}^{-1}$. Red and blue circles depict the $\Delta \chi$ maximum and minimum, respectively. 
obtained based on the warm pool composite WPC1 at the time of peak positive PC1 shown in previous plots. For NDJFM, the composite is similar to the results shown in Fig. 14 of AW3, except the region of maximum moistening is slightly shifted toward the Southern Hemisphere. For JJAS, the strongest moistening occurs along the node in the moisture field to the north of the advancing rainband, collocated in a region of strong easterly wind anomalies.

The contribution of horizontal moisture advection and column processes to the propagation of the rainbands is shown in Figs. 11b and 11c. For NDJFM, moistening within the equatorial belt $\left(15^{\circ} \mathrm{N}-15^{\circ} \mathrm{S}\right)$ is dominated by horizontal moisture advection, which is strongest slightly to the south of the equator. During JJAS, horizontal moisture advection is dominant in the Northern Hemisphere tropics, while column processes are mainly responsible for the eastward propagation of the rainbands along the equator. These results are similar to those of previous studies based on data for all 12 calendar months (e.g., Andersen and Kuang 2012; Kim et al. 2014; Arnold and Randall 2015; AW3), but with the strongest moistening tendencies shifted toward the corresponding summer hemisphere.

The results shown in Fig. 11 indicate that seasonal differences in the pattern of horizontal moisture advection are mainly responsible for the different propagation characteristics of the MJO during JJAS and NDJFM. To further elucidate how these different patterns occur, we further decompose the horizontal advection field into the linear contributions involving the low-frequency background state and the nonlinear term involving the MJO-related anomalies and modulation of high-frequency eddy activity by the MJO:

$$
-(\mathbf{V} \cdot \nabla q)^{*} \approx-\left(\mathbf{V}^{\prime} \cdot \nabla \bar{q}\right)^{*}-\left(\overline{\mathbf{V}} \cdot \nabla q^{\prime}\right)^{*}-\left(\mathbf{V}^{\prime} \cdot \nabla q^{\prime}\right)^{*}
$$

where overbars and primes correspond to the lowfrequency background state and eddy components, respectively. These components are separated by using a 101-point Lanczos filter (Duchon 1979) with a 100-day cutoff period, with the background state corresponding to variability of time scales longer than 100 days and the eddies corresponding to time scales shorter than 100 days. The product fields are then filtered to the MJO time scale using a 20-100-day Lanczos filter and regressed onto the $\Delta \chi$ index. This procedure is similar to that used by Maloney (2009) and Kiranmayi and Maloney (2011), except they used a running mean to separate the low-frequency and eddy components. The first term on the right-hand side describes the horizontal advection of low-frequency moisture by the anomalous winds, the second term is the advection of anomalous moisture by the background winds, and the third term represents the nonlinear advection of the anomalous moisture by the anomalous winds. In agreement with results from Maloney and Dickinson (2003), Kiranmayi and Maloney (2011), and AW3, the nonlinear term is dominated by moisture advection from eddies of frequencies higher than 1 cycle per 20 days (not shown). The other two terms are dominated by interactions of the intraseasonal (20-100 days) anomalies with the lowfrequency background state, so that the terms in Eq. (5) can be expressed in the following form:

$$
\begin{aligned}
-\left(\mathbf{V}^{\prime} \cdot \nabla \bar{q}\right)^{*} & \approx-\left(\mathbf{V}^{*} \cdot \nabla \bar{q}\right)^{*}, \\
-\left(\overline{\mathbf{V}} \cdot \nabla q^{\prime}\right)^{*} & \approx-\left(\overline{\mathbf{V}} \cdot \nabla q^{*}\right)^{*}, \\
-\left(\mathbf{V}^{\prime} \cdot \nabla q^{\prime}\right)^{*} & \approx-\left(\mathbf{V}^{\prime \prime} \cdot \nabla q^{\prime \prime}\right)^{*}
\end{aligned}
$$

where the double primes denote fields that have been 20-day time-scale high-pass filtered.

Following Andersen and Kuang (2012) and Arnold et al. (2013), we assess the relative importance of the terms in Eq. (5) to the propagation of the rainbands by comparing the strength of their projections upon the column-integrated moisture tendency:

$$
S_{t}(F)=\frac{\left\|F \partial\left\langle q^{*}\right\rangle / \partial t\right\|}{\left\|\left(\partial\left\langle q^{*}\right\rangle / \partial t\right)\left(\partial\left\langle q^{*}\right\rangle / \partial t\right)\right\|},
$$

where $F$ is the term in Eq. (5), and $\|(\cdot)\|$ is the integral of $(\cdot)$ over the domain $30^{\circ} \mathrm{N} / \mathrm{S}$ and within $90^{\circ}$ east and west of the reference longitude. The results, shown in Fig. 12, are insensitive to the choice of domain.

In NDJFM, advection of mean moisture by the anomalous meridional flow is the dominant term in the budget, contributing to $\sim 60 \%$ of the total moisture tendency. A dynamical interpretation of this term is offered in Fig. 13a. Poleward flow is clearly evident in both hemispheres from $\sim 80^{\circ}$ to $130^{\circ} \mathrm{E}$, but the meridional advection is stronger in the Southern Hemisphere, where the meridional gradient in mean moisture is strongest, consistent with the stronger moisture tendency in the left column of Fig. 11. The central role that meridional advection plays in the eastward propagation of the MJO during boreal winter is consistent with the results of Kim et al. (2014) and AW3 and with the theoretical framework of Adames and Kim (2016). In contrast, the climatological-mean NDJFM flow, shown in Fig. 13c is weak and contributes little to the eastward propagation of the rain area.

During JJAS, however, both the advection of mean moisture by the anomalous flow $-\left(\mathbf{V}^{\prime} \cdot \nabla \bar{q}\right)^{*}$, and advection of anomalous moisture by the mean zonal flow $\left(-\bar{u} \partial q^{\prime} / \partial x\right)^{*}$ contribute significantly to the propagation 

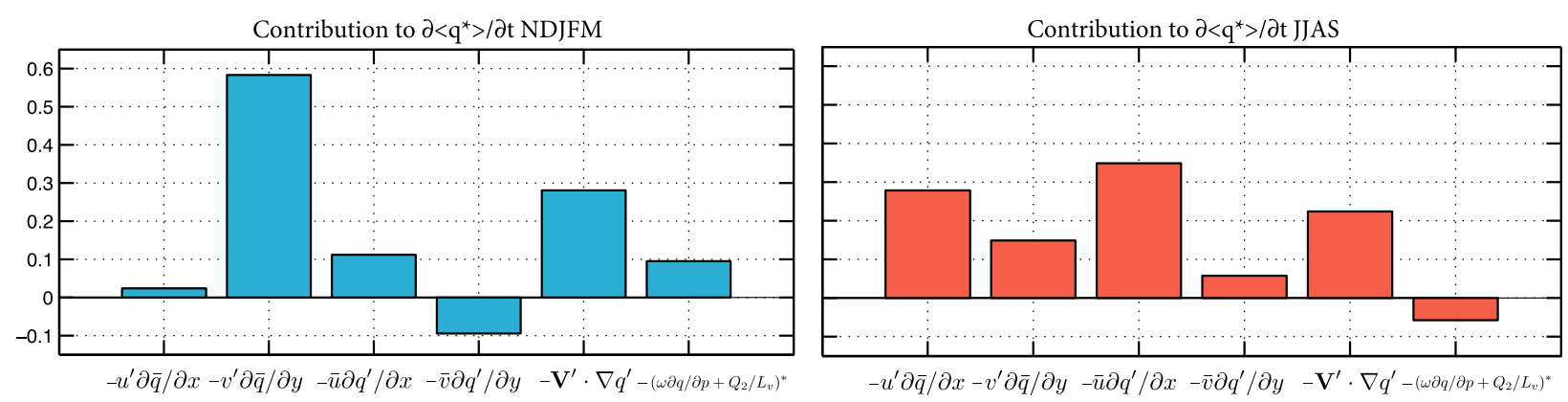

FIG. 12. Normalized contribution of the individual terms in the column-integrated moisture budget [Eqs. (4) and (5)] to the propagation of the moisture anomalies during an MJO cycle composed of warm pool composites. The contributions are obtained by using Eq. (6), projecting each term to the horizontal structure of column-integrated moisture tendency within $90^{\circ}$ to the east and west of the reference longitude and $30^{\circ} \mathrm{N} / \mathrm{S}$ for the warm pool composites centered on PC1 and - PC2 of $\Delta \chi$ (WPC1 and WPC2, respectively).

of the rain areas. The MJO-related easterly wind anomalies along the northern flanks of the rainbands advect humid air westward across India and the Arabian Sea, while the westerly anomalies along the southern flanks advect dry air eastward, thus moving the line of low-level moisture northward, as seen in Fig. 13b and in the five-panel sequences shown in Fig. 8. This pattern of moistening by horizontal advection is responsible for the observed quadrature relationship between OLR and zonal wind anomalies in the time-latitude composites over the northern Indian Ocean sector, shown in Fig. 9. The eastward propagation of the rainbands is enhanced by advection of the rainbands by the climatologicalmean westerly monsoon jet, as seen in Fig. 13d. As the
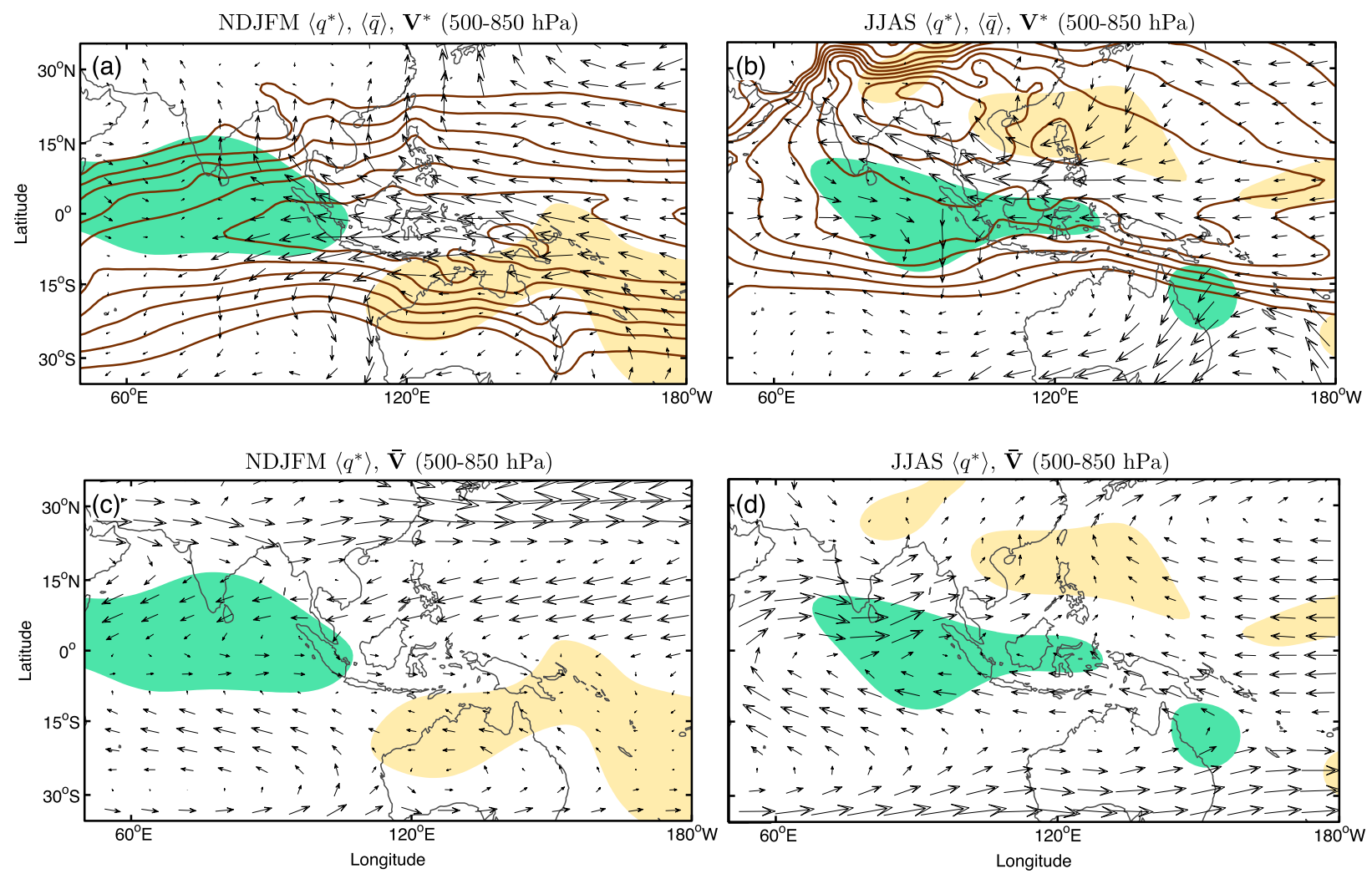

FIG. 13. (top) Mean column-integrated moisture (contours), moisture anomalies (shaded; from $0.5 \mathrm{~kg} \mathrm{~m}^{-2}$ ), and 500-850-hPa-averaged anomalous winds (arrows) at the time of minimum PC2 during (a) NDJFM and (b) JJAS. The MJO-related $\left\langle q^{*}\right\rangle$ anomalies have been horizontally smoothed to improve presentation. (bottom) Moisture anomalies (shaded) at the time of minimum PC2 and 500-850-hPaaveraged mean winds (arrows) during (c) NDJFM and (d) JJAS. The largest wind vectors in (a) and (b) are $1 \mathrm{~m} \mathrm{~s}^{-1}$, while the largest wind vectors in (c) and (d) are $5 \mathrm{~m} \mathrm{~s}^{-1}$. 

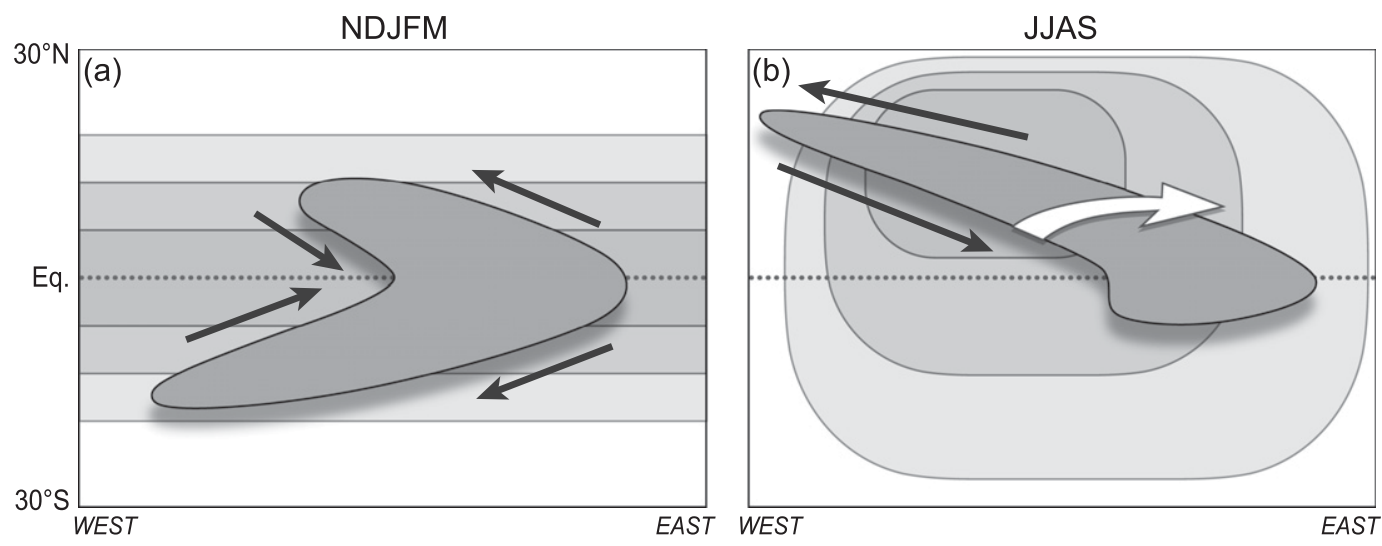

FIG. 14. Schematic describing the mechanisms of propagation of the MJO-related rain area. (a) During NDJFM, anomalous poleward flow (arrows) to the east of the region of enhanced convection (darkest gray shading) advects moisture (lighter gray shading; darker shades of gray indicate higher moisture content) away from the equator, while equatorward flow dries the rain area to the west. (b) During JJAS, easterly wind anomalies along the northern flanks of the rainbands advect humid air westward, while the westerly anomalies along the southern flanks advect dry air eastward, causing northward propagation of the line of low-level moisture. On the eastern flank of the rain area, low-level monsoon flow (large white arrow) advects the eastern flanks of the rainbands eastward.

rainbands propagate toward the northwest Pacific $\left(\sim 10^{\circ} \mathrm{N}\right.$, $\sim 120^{\circ} \mathrm{E}$,) the low-level monsoon flow becomes more southwesterly, enhancing the northward propagation of the rainbands in Fig. 9e. Advection of mean moisture by the anomalous southward flow over the southern Indian Ocean $\sim 90^{\circ} \mathrm{E}$ may account for the southward propagation of the rainbands in Fig. 9d. It is worth noting that horizontal moisture advection by high-frequency eddy activity plays a significant role in the propagation of the rain area during both seasons.

\section{Summary and concluding remarks}

That the MJO is a year-round phenomenon is verified by the similarity of the leading EOFs of the NDJFM and JJAS velocity potential fields shown in Fig. 3. In both seasons, it consists of global-scale upper-level divergence associated with regions of enhanced and suppressed convection that propagate over the Indo-Pacific warm pool $\left(60^{\circ} \mathrm{E}-180^{\circ}\right)$ coupled with anomalies in wind and geopotential that respond to the heating induced by the anomalous convection. As the convective anomalies dissipate over the eastern edge of the warm pool, the velocity potential anomalies lengthen and weaken as they continue to propagate toward the Western Hemisphere. The wave is noticeably weaker during JJAS, and its centers of action are slightly elongated in the westnorthwest-east-southeast direction.

Upper-tropospheric flanking Rossby waves with centers along $28^{\circ} \mathrm{N} / \mathrm{S}$ in the geopotential height field are discernible throughout the year in the winter hemisphere. Through a series of experiments with a shallow-water model in which the upper-level mean flow mediates the wave response to an equatorial heat source, we have shown that the amplitude of the flanking Rossby waves is strongly influenced by the seasonally varying strength of the climatological-mean tropospheric jet streams. Because of this influence, the flanking Rossby waves are strongest in the winter hemisphere even though the diabatic heating that drives the MJO is shifted toward the summer hemisphere.

Although the planetary-scale structure of the MJO is qualitatively similar year-round, the structure of the MJO-related region of enhanced convection in the IndoPacific warm pool region is different during the Asian summer monsoon (JJAS) than during the remainder of the year. In place of the equatorially symmetric swallowtail-shaped pattern described by Zhang and Ling (2012) and in AW2, it assumes the form of an elongated, west-northwest-east-southeast-tilted rainband that coincides with a cyclonic shear line in the lowertropospheric flow. Frictional convergence induces lifting, which maintains the shear line, while horizontal moisture advection causes it to propagate northward. The linear terms involving the climatological-mean moisture $\left(\mathbf{V}^{\prime} \cdot \nabla \bar{q}\right)^{*}$ and wind fields $\left(\overline{\mathbf{V}} \cdot \nabla q^{\prime}\right)^{*}$ both contribute to the moistening of the air to the north and east of the rainband and the drying of the air to the south and west of it. Hence, the Asian summer monsoon circulation and its related west-east moisture gradient over India and the Arabian Sea play an important role in the northward propagation of the rainbands. A schematic showing the mechanisms responsible for northward propagation is shown in Fig. 14b. While many previous studies have 
shown the role of the mean monsoonal flow in advecting the intraseasonal anomalies toward the north (e.g., Jiang et al. 2004; Wu et al. 2006; DeMott et al. 2013), the role of the east-west moisture asymmetry over the Indian subcontinent has not been emphasized to the same degree.

During the remainder of the year, when the maximum in mean column moisture is located over the Maritime Continent, the MJO exhibits more uniform eastward propagation. During these months, the zonal moisture gradient is much weaker than during the summer monsoon months, and the climatological-mean circulation is weaker. The strong meridional gradient in mean moisture along the northern and southern flanks of the warm pool dominates the eastward propagation of the rain area, as shown schematically in Fig. 14a. Because the meridional gradient exhibits similar magnitudes in the Northern and Southern Hemispheres during these months, the poleward propagation of the rainbands is not as pronounced as during JJAS. While frictional convergence is the main mechanism that maintains the shear line during JJAS, lower-free-tropospheric convergence is equally important in maintaining vertical motion during NDJFM. Hence, the MJO-related convection appears to be organized differently during the two contrasting seasons.

Throughout most of the year, the MJO is the dominant mode of intraseasonal variability in the global atmosphere. However, during JJAS it coexists with other modes of intraseasonal variability, including the PacificJapan (PJ) pattern (Nitta 1987; Kosaka and Nakamura 2006, 2010). The degree to which these phenomena are interrelated has yet to be determined.

Acknowledgments. This research was supported by the National Science Foundation's Graduate Research Fellowship Program (NSF-GRFP) Grant DGE-0718124 and by the NSF Grant ATM 1122989. JMW also received partial salary support from the Center for Ocean-LandAtmosphere Studies (COLA). AFA also received financial support from the University of Washington's Graduate Opportunities and Minority Achievement Program (GO-MAP) Stroum Fellowship. We thank George Kiladis and two anonymous reviewers for comments that helped improve the manuscript.

\section{REFERENCES}

Adames, Á. F., and J. M. Wallace, 2014a: Three-dimensional structure and evolution of the MJO and its relation to the mean flow. J. Atmos. Sci., 71, 2007-2026, doi:10.1175/ JAS-D-13-0254.1.

$\longrightarrow$, and $-2014 \mathrm{~b}$ : Three-dimensional structure and evolution of the vertical velocity and divergence fields in the MJO. J. Atmos. Sci., 71, 4661-4681, doi:10.1175/JAS-D-14-0091.1.
— and - 2015: Three-dimensional structure and evolution of the moisture field in the MJO. J. Atmos. Sci., 72, 3733-3754, doi:10.1175/JAS-D-15-0003.1.

— , and D. Kim, 2016: The MJO as a dispersive, convectively coupled moisture wave: Theory and observations. J. Atmos. Sci., 73, 913-941, doi:10.1175/JAS-D-15-0170.1.

Andersen, J. A., and Z. Kuang, 2012: Moist static energy budget of MJO-like disturbances in the atmosphere of a zonally symmetric aquaplanet. J. Climate, 25, 2782-2804, doi:10.1175/ JCLI-D-11-00168.1.

Annamalai, H., J. M. Slingo, K. R. Sperber, and K. Hodges, 1999: The mean evolution and variability of the Asian summer monsoon: Comparison of ECMWF and NCEP-NCAR reanalyses. Mon. Wea. Rev., 127, 1157-1186, doi:10.1175/ 1520-0493(1999)127<1157:TMEAVO>2.0.CO;2.

Arnold, N. P., and D. A. Randall, 2015: Global-scale convective aggregation: Implications for the Madden-Julian oscillation. J. Adv. Model. Earth Syst., 7, 1499-1518, doi:10.1002/ 2015MS000498.

_ Z Z. Kuang, and E. Tziperman, 2013: Enhanced MJO-like Variability at High SST. J. Climate, 26, 988-1001, doi:10.1175/ JCLI-D-12-00272.1.

Bao, M., and D. L. Hartmann, 2014: The response to MJO-like forcing in a nonlinear shallow-water model. Geophys. Res. Lett., 41, 1322-1328, doi:10.1002/2013GL057683.

Barlow, M., M. Wheeler, B. Lyon, and H. Cullen, 2005: Modulation of daily precipitation over Southwest Asia by the MaddenJulian oscillation. Mon. Wea. Rev., 133, 3579-3594, doi:10.1175/ MWR3026.1.

Charney, J. G., and A. Eliassen, 1964: On the growth of the hurricane depression. J. Atmos. Sci., 21, 68-75, doi:10.1175/ 1520-0469(1964)021<0068:OTGOTH > 2.0.CO;2.

Chikira, M., 2014: Eastward-propagating intraseasonal oscillation represented by Chikira-Sugiyama cumulus parameterization. Part II: Understanding moisture variation under weak temperature gradient balance. J. Atmos. Sci., 71, 615-639, doi:10.1175/JAS-D-13-038.1.

Dee, D. P., and Coauthors, 2011: The ERA-Interim reanalysis: Configuration and performance of the data assimilation system. Quart. J. Roy. Meteor. Soc., 137, 553-597, doi:10.1002/ qj. 828 .

DeMott, C. A., C. Stan, and D. A. Randall, 2013: Northward propagation mechanisms of the boreal summer intraseasonal oscillation in the ERA-Interim and SP-CCSM. J. Climate, 26, 1973-1992, doi:10.1175/JCLI-D-12-00191.1.

Duchon, C. E., 1979: Lanczos filtering in one and two dimensions. J. Appl. Meteor., 18, 1016-1022, doi:10.1175/ 1520-0450(1979)018<1016:LFIOAT > 2.0.CO;2.

Gill, A. E., 1980: Some simple solutions for heat-induced tropical circulation. Quart. J. Roy. Meteor. Soc., 106, 447-462, doi:10.1002/qj.49710644905.

Gutzler, D. S., and R. A. Madden, 1989: Seasonal variations in the spatial structure of intraseasonal tropical wind fluctuations. J. Atmos. Sci., 46, 641-660, doi:10.1175/ 1520-0469(1989)046<0641:SVITSS > 2.0.CO;2.

Hoell, A., M. Barlow, and R. Saini, 2012: The leading pattern of intraseasonal and interannual Indian Ocean precipitation variability and its relationship with Asian circulation during the boreal cold season. J. Climate, 25, 7509-7526, doi:10.1175/ JCLI-D-11-00572.1.

Hoyos, C. D., and P. J. Webster, 2007: The role of intraseasonal variability in the nature of Asian monsoon precipitation. J. Climate, 20, 4402-4424, doi:10.1175/JCLI4252.1. 
Jiang, X., T. Li, and B. Wang, 2004: Structures and mechanisms of the northward propagating boreal summer intraseasonal oscillation. J. Climate, 17, 1022-1039, doi:10.1175/ 1520-0442(2004)017<1022:SAMOTN > 2.0.CO;2.

— D. D. Waliser, J.-L. Li, and C. Woods, 2011: Vertical cloud structures of the boreal summer intraseasonal variability based on CloudSat observations and ERA-Interim reanalysis. Climate Dyn., 36, 2219-2232, doi:10.1007/s00382-010-0853-8.

Kemball-Cook, S., and B. Wang, 2001: Equatorial waves and airsea interaction in the boreal summer intraseasonal oscillation. J. Climate, 14, 2923-2942, doi:10.1175/1520-0442(2001)014<2923: EWAASI $>2.0 . \mathrm{CO} ; 2$.

Kikuchi, K., B. Wang, and Y. Kajikawa, 2012: Bimodal representation of the tropical intraseasonal oscillation. Climate Dyn., 38, 1989-2000, doi:10.1007/s00382-011-1159-1.

Kiladis, G. N., K. H. Straub, and P. T. Haertel, 2005: Zonal and vertical structure of the Madden-Julian oscillation. J. Atmos. Sci., 62, 2790-2809, doi:10.1175/JAS3520.1.

Kim, D., J.-S. Kug, and A. H. Sobel, 2014: Propagating versus nonpropagating Madden-Julian oscillation events. J. Climate, 27, 111-125, doi:10.1175/JCLI-D-13-00084.1.

Kiranmayi, L., and E. D. Maloney, 2011: Intraseasonal moist static energy budget in reanalysis data. J. Geophys. Res., 116, 1-12, doi:10.1029/2011JD016031.

Kosaka, Y., and H. Nakamura, 2006: Structure and dynamics of the summertime Pacific-Japan teleconnection pattern. Quart. J. Roy. Meteor. Soc., 132, 2009-2030, doi:10.1256/qj.05.204.

— and - 2010: Mechanisms of meridional teleconnection observed between a summer monsoon system and a subtropical anticyclone. Part I: The Pacific-Japan pattern. J. Climate, 23, 5085-5108, doi:10.1175/2010JCLI3413.1.

Kraucunas, I., and D. L. Hartmann, 2007: Tropical stationary waves in a nonlinear shallow-water model with realistic basic states. J. Atmos. Sci., 64, 2540-2557, doi:10.1175/JAS3920.1.

Krishnamurthy, V., and J. Shukla, 2008: Seasonal persistence and propagation of intraseasonal patterns over the Indian monsoon region. Climate Dyn., 30, 353-369, doi:10.1007/ s00382-007-0300-7.

Lawrence, D. M., and P. J. Webster, 2002: The boreal summer intraseasonal oscillation: Relationship between northward and eastward movement of convection. J. Atmos. Sci., 59, 1593-1606, doi:10.1175/1520-0469(2002)059<1593:TBSIOR >2.0.CO;2.

Lee, J.-Y., B. Wang, M. Wheeler, X. Fu, D. Waliser, and I.-S. Kang, 2013: Real-time multivariate indices for the boreal summer intraseasonal oscillation over the Asian summer monsoon region. Climate Dyn., 40, 493-509, doi:10.1007/s00382-012-1544-4.

Liebmann, B., and C. A. Smith, 1996: Description of a complete (interpolated) outgoing longwave radiation dataset. Bull. Amer. Meteor. Soc., 77, 1275-1277.

Madden, R. A., 1986: Seasonal variations of the 40-50-day oscillation in the tropics. J. Atmos. Sci., 43, 3138-3158, doi:10.1175/ 1520-0469(1986)043<3138:SVOTDO > 2.0.CO;2.

— , and P. R. Julian, 1971: Detection of a 40-50 day oscillation in the zonal wind in the tropical Pacific. J. Atmos. Sci., 28, 702-708, doi:10.1175/1520-0469(1971)028<0702:DOADOI >2.0.CO;2.

_ and - 1972: Description of global-scale circulation cells in the tropics with a 40-50 day period. J. Atmos. Sci., 29, 1109-1123, doi:10.1175/1520-0469(1972)029<1109:DOGSCC > 2.0.CO;2.

-, and —, 1994: Observations of the 40-50-day tropical oscillation-A review. Mon. Wea. Rev., 122, 814-837, doi:10.1175/1520-0493(1994)122<0814:OOTDTO>2.0.CO;2.
Maloney, E. D., 2009: The moist static energy budget of a composite tropical intraseasonal oscillation in a climate model. J. Climate, 22, 711-729, doi:10.1175/2008JCLI2542.1.

— and M. J. Dickinson, 2003: The intraseasonal oscillation and the energetics of summertime tropical western North Pacific synoptic-scale disturbances. J. Atmos. Sci., 60, 2153-2168, doi:10.1175/1520-0469(2003)060<2153:TIOATE $>2.0$.CO;2.

Matsuno, T., 1966: Quasi-geostrophic motions in the equatorial area. J. Meteor. Soc. Japan, 44, 25-43.

Monteiro, J. M., Á. F. Adames, J. M. Wallace, and J. S. Sukhatme, 2014: Interpreting the upper level structure of the MaddenJulian oscillation. Geophys. Res. Lett., 41, 9158-9165, doi:10.1002/ 2014GL062518.

Nitta, T., 1987: Convective activities in the tropical western Pacific and their impact on the Northern Hemisphere summer circulation. J. Meteor. Soc. Japan, 65, 373-390.

Phlips, P. J., and A. E. Gill, 1987: An analytic model of the heatinduced tropical circulation in the presence of a mean wind. Quart. J. Roy. Meteor. Soc., 113, 213-236, doi:10.1002/qj.49711347513.

Salby, M. L., and H. H. Hendon, 1994: Intraseasonal behavior of clouds, temperature, and motion in the tropics. J. Atmos. Sci., 51, 2207-2224, doi:10.1175/1520-0469(1994)051<2207: IBOCTA $>2.0 . \mathrm{CO} ; 2$.

Shukla, R. P., 2014: The dominant intraseasonal mode of intraseasonal South Asian summer monsoon. J. Geophys. Res. Atmos., 119, 635-651, doi:10.1002/2013JD020335.

Waliser, D. E., and Coauthors, 2009: MJO simulation diagnostics. J. Climate, 22, 3006-3030, doi:10.1175/2008JCLI2731.1.

Wang, B., and H. Rui, 1990: Synoptic climatology of transient tropical intraseasonal convection anomalies: 1975-1985. Meteor. Atmos. Phys., 44, 43-61, doi:10.1007/BF01026810.

— , and X. Xie, 1997: A model for the boreal summer intraseasonal oscillation. J. Atmos. Sci., 54, 72-86, doi:10.1175/ 1520-0469(1997)054<0072:AMFTBS > 2.0.CO;2.

Wheeler, M. C., and H. H. Hendon, 2004: An all-season real-time multivariate MJO index: Development of an index for monitoring and prediction. Mon. Wea. Rev., 132, 1917-1932, doi:10.1175/1520-0493(2004)132<1917:AARMMI>2.0.CO;2.

Wolding, B. O., and E. D. Maloney, 2015: Objective diagnostics and the Madden-Julian oscillation. Part II: Application to moist static energy and moisture budgets. J. Climate, 28, 77867808, doi:10.1175/JCLI-D-14-00689.1.

Wu, M.-L. C., S. D. Schubert, M. J. Suarez, P. J. Pegion, and D. E. Waliser, 2006: Seasonality and meridional propagation of the MJO. J. Climate, 19, 1901-1921, doi:10.1175/JCLI3680.1.

Yanai, M., S. Esbensen, and J. Chu, 1973: Determination of bulk properties of tropical cloud clusters from large-scale heat and moisture budgets. J. Atmos. Sci., 30, 611-627, doi:10.1175/ 1520-0469(1973)030<0611:DOBPOT > 2.0.CO;2.

Zangvil, A., 1975: Temporal and spatial behavior of large-scale disturbances in tropical cloudiness deduced from satellite brightness data. Mon. Wea. Rev., 103, 904-920, doi:10.1175/ 1520-0493(1975)103<0904:TASBOL > 2.0.CO;2.

Zhang, C., and M. J. McPhaden, 2000: Intraseasonal surface cooling in the equatorial western Pacific. J. Climate, 13, 2261-2276, doi:10.1175/1520-0442(2000)013<2261:ISCITE>2.0.CO;2.

_- and M. Dong, 2004: Seasonality in the Madden-Julian oscillation. J. Climate, 17, 3169-3180, doi:10.1175/ 1520-0442(2004)017<3169:SITMO >2.0.CO;2.

— cillation. J. Atmos. Sci., 69, 65-78, doi:10.1175/JAS-D-11-081.1. 